\title{
Influences of Maternal Factors Over Offspring Allergies and the Application for Food Allergy
}

\author{
Takashi Fujimura ${ }^{1,2 \dagger}$, Shelly Zing Chin Lum ${ }^{1 \dagger}$, Yuka Nagata ${ }^{1,3}$, Seiji Kawamoto ${ }^{2}$ and \\ Michiko K. Oyoshi ${ }^{1,4 *}$ \\ ${ }^{1}$ Division of Immunology, Boston Children's Hospital, Boston, MA, United States, ${ }^{2}$ Hiroshima Research Center for Healthy \\ Aging (HiHA), Graduate School of Advanced Sciences of Matter, Hiroshima University, Higashi-Hiroshima, Japan, ${ }^{3}$ Division of \\ Gastrointestinal Pathophysiology, Institute of Natural Medicine, University of Toyama, Toyama, Japan, ${ }^{4}$ Department of \\ Pediatrics, Harvard Medical School, Boston, MA, United States
}

OPEN ACCESS

Edited by:

Shohei Hori,

The University of Tokyo, Japan

Reviewed by:

Jun Kunisawa,

National Institutes of Biomedical Innovation, Health and Nutrition,

Japan

Yosuke Kurashima

Chiba University, Japan

*Correspondence:

Michiko K. Oyoshi

michiko.oyoshi@childrens.harvard.edu

tThese authors have contributed equally to this work

Specialty section: This article was submitted to Immunological Tolerance and

Regulation,

a section of the journal

Frontiers in Immunology

Received: 18 April 2019

Accepted: 30 July 2019

Published: 23 August 2019

Citation:

Fujimura T, Lum SZC, Nagata Y, Kawamoto S and Oyoshi MK (2019) Influences of Maternal Factors Over Offspring Allergies and the Application for Food Allergy.

Front. Immunol. 10:1933.

doi: 10.3389/fimmu.2019.01933
The prevalence of food allergy has been steadily rising worldwide with the highest incidence noted among younger children, and increasingly recognized as a growing public concern. The first known ingestion of foods often causes allergic reaction, suggesting that sensitization of offspring with food allergens may occur during pregnancy and/or through breastfeeding. This creates a milieu that shapes the neonatal immune responses to these allergens. However, the effects of maternal allergen exposure and maternal sensitization with allergens on development of allergies in offspring remain controversial. This review discusses recent advances from human data in our understanding of how maternal factors, namely, food allergens, allergen-specific immunoglobulins, cytokines, genetics, and environmental factors transferred during pregnancy or breastfeeding influence offspring allergies and how such effects may be applicable to food allergy. Based on information obtained from mouse models of asthma and food allergy, the review also dissects the mechanisms by which maternal factors, including the impact of immune complexes, transforming growth factor- $\beta$, vitamin $A$, and regulatory T-cell responses, contribute to the induction of neonatal tolerance vs. development of allergic responses to maternally transferred allergens.

Keywords: allergen, asthma, breast milk, food allergy, immune complexes, immunoglobulins, in utero, environmental factors

\section{INTRODUCTION}

The rise in the prevalence of allergic diseases such as asthma, pollinosis, and food allergy has continued worldwide for more than 50 years and has become a global public health concern, especially in young children. Sensitization rate to one or several allergens among school children are approaching 40 to $50 \%$ worldwide (1). Consistently, a recent cohort study identified $32 \%$ of children in southern Sweden suffered with at least one allergic disease and 33\% of them develop multiple allergies (2).

Food allergy currently affects $5-8 \%$ of the United States population (3). The prevalence of food allergy in young children could grow as rapidly as $1 \%$ in a decade (4). Diagnosis of food allergy by food challenge or a combination of history of clinical symptoms and indication of food-specific immunoglobulin (Ig) E by skin prick tests or blood tests (5) provide compelling 
data that the incidence of food allergy is increasing in both Western and developing countries (6). Such escalation in the prevalence of food allergy has been stated as the second wave of the allergy epidemic after asthma (6). Food allergy is adverse immune responses to normally harmless food allergens that result in clinical symptoms implicating the dermatologic, respiratory, gastrointestinal, cardiovascular, and neurologic systems. Eight major food allergens (milk, egg, peanut, tree nuts, wheat, soy, fish, and crustacean shellfish) (7) cause most of the serious food allergy reactions in the United States. Peanut is the most common food allergen in Europe and in the United States and its prevalence in young population under 18-year-old increased from $0.2 \%$ in 1997 to $1.1 \%$ in 2008 (8). Food allergy is the most common reasons for potentially life-threatening anaphylaxis in children. The numbers of visit to a large academic pediatric emergency department for food-induced anaphylaxis has been more than doubled from 2001 to 2006 (9). There are currently limited options of management and treatment for food allergy, including avoidance of causal allergic foods, treatment of accidental exposures with epinephrine, and allergen-specific immunotherapy (10), and additional therapeutic and preventive approaches are urgently needed.

The first known ingestion of foods often causes allergic reactions (11), suggesting that exposure of offspring to food allergens that shape neonatal immune system may occur during pregnancy and/or through breastfeeding. However, the effects of maternal factors on the development of food allergy in offspring are poorly understood. Epidemiological studies in humans have shown conflicting results regarding the role of maternal allergen exposure in the development of allergies in offspring. Past studies have identified an increased risk (12) or no association (13) of maternal peanut consumption with peanut sensitization in offspring. In contrast, maternal exposure and sensitization to food allergens could be protective of offspring from allergic diseases in humans and in mice (14-19). In this review, we highlight recent research advances in the understandings from mouse and human studies of protective and adverse impacts of maternal factors in the development of allergies and food allergy in children with a focus on maternal factors including allergens, immunoglobulins (Igs), immune complexes (IC), cytokines transferred from mothers to offspring in utero and via breast milk, together with genetic and environmental factors that could further facilitate the neonatal immune responses to allergens.

\section{MATERNAL PROTECTIVE INFLUENCES OVER OFFSPRING ALLERGY}

\section{Human Studies}

Maternal allergen consumption during their pregnancy and breastfeeding has been thought to control allergen sensitization

\footnotetext{
Abbreviations: AIT, Allergen-specific immunotherapy; aRR, Adjusted rate ratio; CT, cholera toxin; DC, dendritic cell; FCRn, neonatal Fc receptor; Foxp3, forkhead box p3; IC, immunecomplex; IFN, interferon; Ig, immunoglobulin; IL, interleukin; i.p., intraperitoneal; mMCP1, mouse mast cell protease I; OR, odds ratio; OVA, ovalbumin; PUFAs, polyunsaturated fatty acids; $\operatorname{sgA}$, secretary IgA; TGF- $\beta$, tumor growth factor $\beta$; Th, helper T cell; Treg, regulatory T cell; WT, wild type.
}

in offspring, because first contact to food allergens could occur in utero as major food allergens could appear in amniotic fluid in an intact form (20). Contrarily, maternal nutrition status, allergens, and Igs, transferred in utero and via breast milk may prevent allergic sensitization in children. Two decades ago, United Kingdom Government's Chief Medical Officer's Committee on Toxicity of Chemicals in Food, Consumer Products and the Environment (COT) recommended that atopic mothers should avoid consumption of peanut and peanut products during pregnancy and breastfeeding to prevent peanut allergy in offspring. Following this recommendation, however, the prevalence of peanut allergy in school-age children increased and even resulted in the highest prevalence of peanut allergy in 4 - to 5-year-old children (21). These data indicate no significant preventive effect by maternal allergen avoidance. Further, maternal dietary restriction during pregnancy or breastfeeding that aimed to prevent offspring allergy did not show a significant protective effect, instead, resulted in a lower gestational weight gain or adverse effects in maternal nutrition and fetal growth (22, 23). More recent studies have implied that the effect of maternal diet should be considered together with postnatal introduction of food in offspring (24-26). These studies underscore the requirement of alternative strategies rather than maternal dietary antigen avoidance for the prevention of food allergy (Table 1). In this section, we focus on the effects of maternal nutrition in utero and via breastfeeding on prevention of allergies in children.

\section{In utero Factors}

\section{Food allergen consumption}

Reducing the risk of allergy by dietary means is a logical response to the increase in food allergy and other allergic diseases. In contrast to maternal allergen avoidance, prenatal consumption of potentially allergenic foods has been shown to prevent allergic sensitization in children. A study enrolled 6,288 children in Finland showed an association between high ingestion of milk products during pregnancy and a lower risk of cow's milk allergy in children [odds ratio (OR), 0.56] (27). The preventive effects were observed in children of non-allergic mother (OR, 0.30). Maternal ingestion of milk products was correlated with levels of beta-casein-specific IgA in cord blood in children without cow's milk allergy. Consequently, the study suggested that maternal milk ingestion during pregnancy exhibits tolerogenic effects in utero especially in non-allergic mothers. In a recent prospective study with 8,205 children between 10- and 14-year-old, the prevalence of peanut or tree nuts allergy in offspring was lower in children of non-allergic mothers who ingested at least five servings of peanut/tree nuts per week during pregnancy (OR, 0.31) (15). However, there was no association of maternal consumption of peanut/tree nuts during pregnancy and the risk of peanut/tree nuts allergy in offspring of mothers who were allergic to peanut/tree nuts, indicating that this preventive effect may be operative in non-allergic mothers but not in allergic mothers (15). Another cohort study in United States enrolled 1,277 mother-child pairs reported that maternal diet during pregnancy was associated with decreased allergy and asthma in mid-childhood (mean age, 7.9-year-old) (14). Higher maternal consumption of peanut during the first trimester was associated 
TABLE 1 | Maternal and offspring food consumption and the outcomes in offspring allergy in human cohort studies.

\begin{tabular}{|c|c|c|}
\hline Readout & Population/size & Dose/duration/ \\
\hline \multicolumn{3}{|l|}{ IN UTERO } \\
\hline $\begin{array}{l}\text { Cow's milk allergy } \\
\text { in children }\end{array}$ & 6,288 children & During pregna \\
\hline $\begin{array}{l}\text { Peanut or Tree nuts allergy } \\
\text { in offspring }\end{array}$ & $\begin{array}{l}\text { 8,205 children (10 to } 14 \\
\text { years of age) }\end{array}$ & During pregna \\
\hline
\end{tabular}

$$
\text { in offspring years of age) }
$$

Allergy and asthma

in mid-childhood

Peanut sensitization in offspring

Peanut allergy

Maternal avoidance and avoidance of solid and allergic food in childhood
1,277 mother-child pairs

$(7.93 \pm 0.82$ years of age)
503 infants ( 3 to 15 months of age) with likely milk or egg allergy without previous diagnosis of peanut allergy peanut

13,971 children of non-atopic and atopic mothers (1 to 18 months of age)

288 infants of atopic parents $(4,12$, and 24 months of age)
During pregnancy
- The first or second trimester of pregnancy or during breastfeeding - The third trimester of pregnancy
- Never breastfed with frequent consumption of during pregnancy

\section{During pregnancy}

\section{- Maternal food} avoidance during the third trimester of pregnancy and breastfeeding period
Association of high consumption Protective

of milk products during pregnancy with a lower risk of cow's milk allergy in offspring of non-allergic mothers

- Association of maternal consumption of at least five servings of peanut/tree nuts per week with a lower prevalence of peanut or tree nut allergy in offspring of non-allergic mothers - No association of maternal consumption of peanut/tree nuts with the prevalence of peanut or tree nuts allergy in offspring of peanut/tree nuts-allergic mothers Association of higher maternal consumption of (1) peanut during the first trimester with a reduced risk of peanut allergic reaction, (2) milk during the first trimester with reduced asthma and allergic rhinitis, and (3) wheat during the second trimester with reduced atopic dermatitis in offspring

- No significant effect of maternal peanut consumption on offspring peanut sensitization

- A dose-dependent association of maternal peanut consumption during the third trimester of pregnancy with peanut sensitization in offspring

A strong association of maternal . Allergic

No association

Allergic

- Protective (non-allergic mothers)

- No association

(allergic mothers)

Protective

peanut consumption with peanut sensitization in offspring

No association of maternal peanut No association consumption during pregnancy with challenge-proven peanut allergy in preschool children

- Association of maternal food avoidance with a lower cumulative prevalence of atopy in offspring at 12 months, occurring from reduced food-associated atopic dermatitis, urticaria, and/or gastrointestinal disease, as compared to offspring of mothers with unrestricted diets

- Offspring avoidance of . Association of offspring food solid food for 6 months, avoidance with a significant avoidance of cow's milk, suppression of the prevalence of corn, citrus, and wheat food allergy and milk sensitization for 12 months, and avoidance of egg, peanut, and fish for 24 months
- Protective before 2 years of age.

- No association of offspring food . No association (at 7 years avoidance with the prevalence in of age) food allergy, atopic dermatitis, allergic rhinitis, asthma, any atopic disease, and serum lgE levels at 7 years of age 
TABLE 1 | Continued

\begin{tabular}{|c|c|c|c|c|c|}
\hline Readout & Population/size & Dose/duration/timing & Association/outcome & Effects & References \\
\hline \multicolumn{6}{|l|}{ BREASTFEEDING } \\
\hline $\begin{array}{l}\text { Peanut sensitization at } 7 \\
\text { years of age }\end{array}$ & $\begin{array}{l}342 \text { infants (7 years } \\
\text { of age) }\end{array}$ & $\begin{array}{l}\text { During breastfeeding } \\
\text { and direct peanut } \\
\text { introduction to infants }\end{array}$ & $\begin{array}{l}\text { - Lowest prevalence of peanut } \\
\text { sensitization in infants whose } \\
\text { mothers consumed peanut while } \\
\text { breastfeeding with an early direct } \\
\text { introduction of peanut before } 12 \\
\text { months of age } \\
\text { - Increased risk of peanut } \\
\text { sensitization in infants whose } \\
\text { mothers consumed peanut while } \\
\text { breastfeeding with delayed } \\
\text { introduction of peanut beyond } 12 \\
\text { months of age, or maternal } \\
\text { peanut avoidance with an early } \\
\text { direct introduction of peanut by } \\
12 \text { months of age }\end{array}$ & $\begin{array}{l}\text { Protective } \\
\text { (infants breastfed with early } \\
\text { introduction) } \\
\text { - Allergic } \\
\text { (infants breastfed with } \\
\text { delayed introduction) }\end{array}$ & (26) \\
\hline Food allergy & $\begin{array}{l}649 \text { children with } \\
\text { challenge-proven food } \\
\text { allergy ( } 5 \text { to } 214 \text { months } \\
\text { of age) }\end{array}$ & $\begin{array}{l}\text { Direct breastfeeding } \\
\text { or bottle-feeding }\end{array}$ & $\begin{array}{l}\text { - Every additional month of } \\
\text { breastfeeding decreased a risk for } \\
\text { food allergy by } \sim 4 \% \text { per month. } \\
\text { - No significant association } \\
\text { between the prevalence of food } \\
\text { allergy and direct breastfeeding } \\
\text { vs. bottle-feeding }\end{array}$ & Protective & (31) \\
\hline Childhood asthma & $\begin{array}{l}3,296 \text { children ( } 3 \text { years } \\
\text { of age) }\end{array}$ & $\begin{array}{l}\text { Direct breastfeeding } \\
\text { - Indirect breastfeeding }\end{array}$ & $\begin{array}{l}\text { - Direct breastfeeding was more } \\
\text { protective against childhood } \\
\text { asthma at } 3 \text { years of age as } \\
\text { compared to formula-feeding. } \\
\text { - Indirect breastfeeding } \\
\text { (breastfeeding with some } \\
\text { expressed breast milk) provided } \\
\text { an intermediate protection as } \\
\text { compared to direct breastfeeding. }\end{array}$ & - Protective & (32) \\
\hline \multicolumn{6}{|l|}{ EARLY INTRODUCTION } \\
\hline $\begin{array}{l}\text { Peanut allergy } \\
\text { (LEAP) }\end{array}$ & $\begin{array}{l}834 \text { infants ( } 4 \text { to } 10 \\
\text { months of age) at high risk } \\
\text { for allergy }\end{array}$ & $\begin{array}{l}\text { Food introduction } \\
\text { between } 4 \text { and } 10 \\
\text { months of age }\end{array}$ & $\begin{array}{l}\text { - Among the infants initially } \\
\text { negative for peanut skin-prick } \\
\text { test, the prevalence of peanut } \\
\text { allergy at } 60 \text { months of age was } \\
\text { lower in the consumption group } \\
\text { than those in the avoidance } \\
\text { group. } \\
\text { - Among the infants initially } \\
\text { positive for peanut skin-prick test, } \\
\text { the prevalence of peanut allergy } \\
\text { was lower in the consumption } \\
\text { group than those in the } \\
\text { avoidance group. }\end{array}$ & $\begin{array}{l}\text { Protective } \\
\text { (skin-prick test positive infants) }\end{array}$ & $(34,35)$ \\
\hline
\end{tabular}


TABLE 1 | Continued

\begin{tabular}{|c|c|c|c|c|c|}
\hline Readout & Population/size & Dose/duration/timing & Association/outcome & Effects & References \\
\hline $\begin{array}{l}\text { Food allergy } \\
\text { (EAT) }\end{array}$ & $\begin{array}{l}\text { 1,303 infants ( } 3 \text { months } \\
\text { of age) }\end{array}$ & $\begin{array}{l}\text { Food introduction before } \\
6 \text { months of age }\end{array}$ & $\begin{array}{l}\text { - Multiple allergenic foods can be } \\
\text { safely introduced into infant diet } \\
\text { without adverse influence on } \\
\text { breastfeeding. } \\
\text { - Significantly lower prevalence of } \\
\text { any food allergy in the early } \\
\text { introduction group in families that } \\
\text { closely adhered to the } \\
\text { challenging protocol }\end{array}$ & $\begin{array}{l}\text { Safe early introduction of } \\
\text { allergenic foods } \\
\text {. Protective }\end{array}$ & (36) \\
\hline
\end{tabular}

EAT, Enquiring About Tolerance; LEAP, Learning Early About Peanut Allergy.

with $47 \%$ reduced odds of peanut allergen reaction (OR, 0.53). Higher maternal milk ingestion during the first trimester was also associated with reduced risk of asthma (OR, 0.83) and allergic rhinitis (OR, 0.85). Maternal consumption of wheat during the second trimester was associated with reduced risk of atopic dermatitis (OR, 0.64). These results indicate that early encounter with food allergens through maternal diet during the critical period of fetal development during the first trimester may lead to tolerance rather than sensitization. Collectively, these studies suggest that maternal allergen consumption during pregnancy could be beneficial to prevent allergic sensitization in offspring.

\section{Allergen-specific Igs}

Placental transfer of maternal Igs is known to provide a protective passive immunity to the fetus against infection (37). The selective transport of maternal IgG to the fetus during pregnancy is mediated by the neonatal Fc receptor (FcRn) expressed in placental syncytiotrophoblast (38). Allergen-specific immunotherapy (AIT) appears safe in pregnant women (39) and placental transfer of allergen-specific IgG1 and IgG4 antibodies, but not IgE, from AIT-treated mothers to offspring has been shown (40). Consistently, children of AIT-treated mothers during pregnancy exhibited high levels of IgG antibodies and fewer positive skin prick test as compared with children of untreated mothers (41). Increased levels of cord blood IgG antibodies to cat and birch were associated with less atopic symptoms in the children of allergic mothers during the first 8 years of life (42). These results suggest that maternal allergen-specific IgG antibodies may reduce the development of offspring atopy, but further data are required regarding a potential protective role of placentally transferred allergen-specific IgG toward allergic diseases, particularly food allergy in offspring.

\section{Microbiota}

Over the last decade, the importance of commensal bacteria in the host immune responses has been increasingly recognized, particularly bacteria colonizing the gastrointestinal tract. The composition of intestinal microbiota in newborn infants is dependent on many factors, such as type of maternal deliveries. Cesarean delivery has been associated with the incidence of atopy and allergic diseases in children, including atopic dermatitis, rhinitis, asthma, and eosinophilic esophagitis (4346). Through vaginal delivery, offspring ingest maternal vaginal and colonic microbiota with passage through the birth canal, which probably represents the most important phase of initial gut colonization. This exposure of newborn infants to maternal bacteria results in stimulation of toll-like receptor (TLR) and production of interleukin (IL)-12 and interferon (IFN)- $\gamma$, which promote the differentiation of naïve helper $\mathrm{T}$ (Th) cells into Th1 effector cells that secrete $\operatorname{IFN}-\gamma(44,47)$. Cesarean section was associated with reduced pro-inflammatory cytokine responses to TLR1/2 stimulation, followed by an increased abundance of bacterial colonization in the airway during late infancy, therefore increasing the risk of infantile wheezing (48). Levels of transforming growth factor (TGF)- $\beta 1$ were lower in newborns following cesarean section (49). Hence, newborns born through vaginal delivery and exposed to higher levels of TGF- $\beta 1$ may exhibit more protection toward atopy at later life, potentially reflecting the capacities of TGF- $\beta 1$ to skew the production of IgE toward non-inflammatory isotypes IgG4 and IgA (50). Additional long-term studies of investigating maternal microbiota and its relationship with infant microbiota, as well as the development of infant food allergy are needed.

\section{Dietary supplements}

Development of human immune system begins in utero and continues after birth (51). Nutrition influences the global health and disease of children in early life. During the last decade, many examples showed prevention of allergic sensitization in children by modifying maternal diet during pregnancy $(52,53)$, indicating an in utero programming of allergic susceptibility in offspring. Increased levels of 25-hydroxyvitamin D (25(OH)D) in cord blood have been inversely associated with the risk of asthma and wheeze during childhood (54). Rationally, the association of maternal vitamin $\mathrm{D}$ supplementation with the development of atopic diseases in offspring has been investigated. In Vitamin D Antenatal Asthma Reduction Trial (VDAART), 806 women between the gestational ages of 10 to 18 weeks were supplemented with daily vitamin D for 22 to 30 weeks (55). Maternal supplementation with high-dose (4,000 IU/d) vitamin $\mathrm{D}$ reduced the risk of asthma and recurrent wheezing in offspring by 3 years of age $(56,57)$. In Copenhagen Prospective Studies on Asthma in Childhood in 2010 (COPSAC2010), 623 pregnant women were administered daily 2,400 IU/d vitamin D3 from the gestational ages of 24 week to 1 week postpartum (58). Combined analysis of these two studies demonstrated $25 \%$ reduced risk 
of asthma and recurrent wheeze at $0-3$ years of age (adjusted OR, $0.74 ; p=0.02$ ) by maternal vitamin $\mathrm{D}$ supplementation (59). Of note, high concentration of serum maternal $25(\mathrm{OH}) \mathrm{D}$ was associated with an increased incidence of allergic airway disease in offspring at 20-25 years of age (60). With regard to food allergy, vitamin $\mathrm{D}$ insufficiency early in life has been associated with the risk of food allergy (61). In addition, maternal prenatal vitamin D supplementation was inversely associated with the development of food allergy, especially in infants with polymorphisms that increases the biological availability of serum vitamin $\mathrm{D}$ (62). These heterogeneous findings may reflect the importance of context, timing, and dose of vitamin $\mathrm{D}$ in the actions on the offspring allergies and potential differences in the mechanisms of asthma and food allergy.

Early exposure of omega $6(n-6)$ and omega 3 (n-3) polyunsaturated fatty acids (PUFAs), commonly found in many nuts, seeds, and vegetable oils, during pregnancy shows different capacities to alter the incidence of atopic sensitization and allergy in children (63). Arachidonic acid (20:4, n-6) is a catabolite of linoleic acid (18:2, n-6) and a main substrate for eicosanoids, which are a family of lipid mediators that induce inflammation $(63,64)$. Higher consumption of $\mathrm{n}$ 3 , such as docosahexaenoic acid and eicosapentaenoic acid primarily found in certain fish, decreased the levels of inflammatory eicosanoids from arachidonic acid and increased the levels of alternative eicosanoids that have anti-inflammatory properties (63). Maternal intake of oily fish containing higher docosahexaenoic acid and eicosapentaenoic acid as well as fish oil supplements showed protective effects on wheeze and asthma in offspring (65). Similarly, maternal fish oil supplementation reduced the severity of atopic eczema and the risk of egg sensitization in 1-year-old offspring (66). High maternal intake of $\alpha$-linoleic acid (18:3), another $n-3$ found in plant sources such as nuts and seeds, was associated with decreased risk of wheeze in Japanese children at 16- to 24-month-old (67). Taken together, maternal intake of n-3 PUFAs may have beneficial effects on preventing atopic disorders in offspring, including wheeze and asthma (63), although its preventive effect against food allergy is not clear (68). Whether these results reflect a generally healthier diet remains to be determined. The role of $n-6$ in offspring allergy will be discussed in section Dietary Supplements in Human Studies for maternal allergic influences.

\section{Breastfeeding \\ Food allergen consumption}

The recent clinical report by American Association of Pediatrics (AAP) proposes that no conclusions can be drawn regarding the effects of breastfeeding on preventing or delaying the development of food allergies in offspring (69), however, the report also recognizes that there is now evidence that early peanut introduction may prevent peanut allergy, as discussed below. The recent groundbreaking Learning Early About Peanut Allergy (LEAP) trial in the UK showed that introducing peanuts to infants at high risk for allergy at 4 to 10 months of age reduces the incidence of peanut allergy (34). The study recruited 834 infants with mild eczema with no egg allergy and infants with severe eczema, egg allergy, or both and subdivided based on peanut wheal responses by skin prick test into 0 -, 1- to 4-, and $>4-\mathrm{mm}$ groups (35). All infants with mild eczema with no egg allergy showed no peanut-specific IgE sensitization, but $91 \%$ of the group with $>4$-mm peanut wheal responses exhibited peanut-specific IgE sensitization. The infants at the high risk for peanut allergy were randomly assigned to ingest or avoid peanut until 60 months of age $(N=640)$. Among the infants who were initially negative for skin-prick test $(N=530)$, the prevalence of peanut allergy at 60 months of age was considerably lower in the consumption group (1.9\%) than those in the avoidance group (13.7\%). Among the infants who were initially positive for skin-prick test $(N=98)$, the prevalence of peanut allergy was $10.6 \%$ and $35.3 \%$ in the consumption group and in the avoidance group, respectively $(p=0.004)$. Interestingly, levels of peanut-specific IgG4 were increased in the consumption group whereas levels of peanut-specific IgE were increased in the avoidance group. The study concluded that early introduction of peanut reduced the development of peanut allergy in highrisk children and that early peanut introduction does not prevent other allergies (asthma, seasonal rhinoconjunctivitis, perennial rhinoconjunctivitis, and eczema), sensitization to other food allergens (egg, milk) and aeroallergens, or reported allergic reactions to tree nuts and sesame (70). A follow-up Enquiring About Tolerance (EAT) trial in the UK with 1,303 infants demonstrated that early introduction of 6 allergenic foods [cow's milk, peanut, hard-boiled hen's egg, sesame, whitefish (cod), and wheat] was achievable by 6 months of age and did not affect breastfeeding (36). The study recruited exclusively breast-fed infants from 3 months of age and randomly assigned to standard introduction group (SIG) or early introduction group (EIG). The EIG was introduced 6 allergenic foods alongside continuous breastfeeding until at least 6 months of age. The study showed multiple allergenic foods can be safely introduced into infant diet without adverse influence on breastfeeding. The results failed to show better efficacy of early introduction in the prevention of food allergy to one or more of the 6 intervention foods: food allergy developed in 7.1 and $5.6 \%$ of the participants in the SIG and in the EIG, respectively $(p=0.32)$. However, in families that closely adhered to the challenging protocol, the prevalence of any food allergy was considerably lower in the EIG than in the SIG ( 2.4 vs. $7.3 \%, p=0.01$ ), as was the incidence of peanut allergy ( 0 vs. $2.5 \%, p=0.003$ ) and egg allergy (1.4 vs. $5.5 \%, p=0.009$ ). There was no significant effect with respect to the prevalence of allergy to milk, sesame, fish, or wheat. These studies suggest that the early introduction of all 6 allergic foods, although not easily achieved, may have beneficial effects in preventing food-allergen sensitization in high-risk children.

In addition to early direct food introduction to children, maternal consumption of potentially allergic foods during breastfeeding has been suggested to prevent food sensitization in offspring. A Canadian cohort study with 342 infants analyzed the association of maternal peanut consumption while breastfeeding, timing of direct peanut introduction to infants, and a combination of both, with peanut sensitization at 7 years of age (26). Breastfeeding and peanut consumption by mothers and infants were captured by repeated questionnaires during infancy. The lowest prevalence of sensitization with peanut was observed 
in infants whose mothers consumed peanut while breastfeeding and who were directly introduced peanut before 12 months of age (1.7\%). Maternal peanut consumption with delayed introduction of peanut to infants beyond 12 months of age or maternal peanut avoidance with a direct introduction of peanut by 12 months of age was associated with an increased risk of peanut sensitization $(p=0.003)$ (15.1 and $17.6 \%$, respectively). These results suggest that a combination, but not alone, of maternal peanut consumption while breastfeeding and direct introduction of peanut in the first year of life provides a significant protection from peanut sensitization. Although the readout was peanut sensitization and not challenge-proven peanut allergy, this study raises an important point that the combination of maternal and offspring factors together during breastfeeding period plays a critical role in the prevention of food allergy in offspring.

\section{Allergen, allergen-specific Igs, and cytokine}

Maternal food allergen consumption results in an appearance of allergen in breast milk, though not always. Ara h 2 and Ara h 6 are detectable in breast milk (71). Ara h 6 appeared in breast milk from non-atopic peanut-tolerant mothers as early as $10 \mathrm{~min}$ after peanut ingestion and continued being detected over a 24$\mathrm{h}$ period (72). IC consisting of allergen and allergen-specific IgG and IgA were present in breast milk. Such human milk containing peanut allergens and IC induced a partial oral tolerance in peanut-sensitized young mice (72), indicating a protective role of milk-born allergen in reducing disease susceptibility in offspring. Microarray technology revealed that allergen-specific IgG and IgE antibodies are transmitted from maternal blood into breast milk and that breast milk IgG pattern mirrored the profile of IgG reactivity in maternal blood (73), which suggest a possibility that the transmission of allergen-specific Igs from mothers to offspring via milk may affect the development of allergy in neonates. Our recent study demonstrated that allergen-specific IgG in milk may play a crucial role in protection of offspring from food allergy as IC. Our study showed that ovalbumin (OVA)-specific IgG4 was detectable in 10 subjects among 16 breast milk samples from non-atopic mothers. OVA-IgG4-IC were detectable in 8 of 10 mothers who had OVA-IgG4 (74). Importantly, supplementation of humanized mice expressing human FcRn constitutively with human breast milk containing OVA-IgG-IC resulted in protection of those mice against food allergic responses, suggesting a critical role of maternal IgG-IC in breast milk in the induction of tolerance against food allergy. These results, together with our mouse studies as discussed below (section Breastfeeding in Mouse Studies for maternal protective influences), imply that the concept of IgG-IC contributing to protection against food allergy may extend to humans (74).

Maternal cow's milk avoidance was associated with lower levels of milk allergen-specific IgA and IgG4 antibodies and the development of cow's milk allergy in infants (75). High concentration of milk allergen-specific IgA in breast milk significantly reduced transcytosis of milk allergen through gut lumen, suggesting that IgA may prevents excessive, uncontrolled food antigen uptake in the gut lumen and thus in the prevention of cow's milk allergy. The Prediction of Allergies in Taiwanese Children (PATCH) birth cohort study assessed levels of secretary
$\operatorname{IgA}(\operatorname{sg} \mathrm{A})$ in colostrum and stool from infants within 5 days after birth and at 2 and 4 months of age (76). sIgA concentration in colostrum was significantly higher in allergic mothers than those in non-allergic mothers $(p=0.01)$. Fecal sIgA concentration in breastfed infants was significantly higher in those in formulafed infants $(p<0.05)$. The association of breastfeeding with the increased levels of fecal $\operatorname{sg} A$ in infants may suggest potential protective effects in early life.

A systematic review suggests a positive association between concentration of TGF- $\beta 1$ or TGF- $\beta 2$ in breast milk and a reduction in IgE titer and atopic inflammation in infancy and early childhood (77). In contrast, a prospective study with 398 mothers demonstrated an association of higher eczema risk with higher concentration of TGF- $\beta 2$ in breast milk (OR, 1.04) at 6 months of age (78). Interestingly, detectable levels of IL13 in colostrum were associated with lower parental-reported food allergy (OR, 0.10) at 6 months of age (78). High levels of IL-1 $\beta$, IL-17, and C-C motif chemokine ligand (CCL) 17 (TARC) and low levels of C-X-C motif chemokine ligand (CXCL) 1 and thymic stromal lymphopoietin (TSLP) in breast milk were associated with a low risk of eczema at $0-3$ years of age (79). Although the mechanisms are unknown and further large clinical studies are needed to confirm these results, allergens, IgG, IgA, and regulatory cytokines such as TGF- $\beta$ in breast milk likely orchestrate to develop and maintain appropriate neonatal immune responses and may prevent adverse immunological outcomes in infants.

\section{Breastfeeding duration, feeding modes, and maternal allergy}

Although the beneficial effects of breastfeeding on global health of offspring are recognized, the effects of breastfeeding on the development of allergic diseases in offspring is controversial and remains largely elusive. Regarding the potential beneficial effects of breastfeeding duration on preventing allergies in children has been well-summarized in a recent review by American Academy of Pediatrics (69), although the available human data are still not sufficient to draw firm conclusions regarding various aspects of allergy prevention. Briefly, there is evidence that exclusive breastfeeding for 3 to 4 months decreases the development of eczema before 2 years of age, but there are no short- or longterm benefits of exclusive breastfeeding beyond 3 to 4 months for prevention of atopic diseases (69). Any duration of breastfeeding mode than 3 to 4 months is protective toward wheezing in the first 2 years of life (69). Some evidence suggests that longer duration of any mode of breastfeeding, including partial and exclusive breastfeeding, protects toward asthma even after 5 years of age (69). The role of breastfeeding duration in food allergies is much less clear. A cohort study in Taiwan enrolled 186 children demonstrated that exclusive or partial breastfeeding for longer than 6 months reduced milk sensitization in children at 1 and 1.5 years of age (30) compared to formula-fed children (OR, 0.37). A retrospective cohort study including 649 children with challenge-proven food allergy (31) demonstrated that every additional month of breastfeeding decreased a risk for food allergy by $\sim 4 \%$ per month (OR, 0.96; $p=0.02$ ). Within breastfed children, there was no significant association between the incidence of food allergy and direct breastfeeding 
vs. bottle-feeding ( $p=0.27$ ). Collectively, these studies indicate the association of prolonged breastfeeding with reduced risk of allergic sensitization and food allergy. Regarding feeding modes, a prospective birth cohort study in Canada with 3,296 children examined the effects of infant feeding modes on childhood asthma (32). Among direct breastfeeding alone, breastfeeding with some expressed breast milk, breast milk plus formula, or formula alone, direct breastfeeding was more protective against childhood asthma at 3 years of age as compared to formula-feeding. Indirect breast milk by other modes of infant feeding conferred intermediate protection. The differences in the preventive effects of direct breastfeeding vs. expressed breast milk may reflect a possible alternation of milk factors such as immune cells, cytokines, and microbiota. Maternal allergy may influence the effects of breastfeeding on allergic sensitization in children. A Canadian study that included 2,773 infants compared the effects of breastfeeding on offspring wheezing in the presence or the absence of maternal asthma (33). In the presence of maternal asthma, development of wheezing in infants was reduced by $62 \%$ with exclusive breastfeeding [adjusted rate ratio (aRR), 0.38] and by $37 \%$ with partial breastfeeding (supplemented with solid foods; aRR, 0.38) as compared to infants with no breastfeeding. Partial breastfeeding supplemented with formula was not protective for wheezing in infants (aRR, 0.89). Importantly, such association was not significant in the absence of maternal asthma. The role of breastfeeding duration, feeding modes, and maternal allergies in the development of offspring food allergy needs intensive future studies, however, these results above may favor the concept that longer period of breastfeeding confers protection against allergic diseases in infants.

\section{Perspective}

Maternal diet is not only an important factor for growth of fetus but also likely shapes neonatal immune responses and determines the susceptibilities of offspring to infectious diseases and allergies (80). Nutrition, allergens, Igs, cytokines, and also immune cells are transferred from mothers to neonates via placenta and during breastfeeding and may influence offspring allergy (Table 2). Direct breastfeeding may be beneficial to efficiently transfer protective factors such as microbiota from mothers to offspring. Human studies show conflicting results and whether and how maternal factors transferred in utero, breastfeeding, or both, exert preventive effects toward allergies in children (Tables 1, 2). Future cohort study and meta-analysis with systematic data of allergen consumption (maternal and offspring), immune active milk components together with environmental and genetic factors are needed to answer those questions.

\section{Mouse Studies}

Substantial numbers of mouse studies have reported preventive effects of maternal factors on development of allergic inflammation in offspring such as allergic airway inflammation and food allergic responses (Table 3). Offspring of dams sensitized with allergen or offspring nursed by allergen-sensitized or -exposed dams during breastfeeding show protection from the development of antigen-specific IgE and allergic inflammation following sensitization with allergen $(74,119)$. Many of these studies focus on the role of maternally transferred allergens and IgG via placenta and breast milk to offspring.

\section{Preconceptional and in utero Factors Allergen, allergen-specific Igs, and cytokine}

Several studies reported preventive effects on allergic sensitization and allergic inflammation in offspring born from dams sensitized with or exposed to allergen. Oral administration of wild-type (WT) dams with OVA during pregnancy has been shown to decrease allergen sensitization in offspring (99). Oral administration of dams with high-dose OVA $(9 \mathrm{mg})$ during the first week of pregnancy resulted in a suppression of OVA-specific IgE levels in 3-day-old, but not in 25-day-old, offspring following intraperitoneal (i.p.) sensitization with OVA/alum and i.p. OVA injection (99). Oral administration of dams with low-dose OVA $(1.5 \mathrm{mg})$ during pregnancy resulted in a sustained inhibition of OVA-specific IgE levels both in 3- and 25-day-old offspring. Fifty-seven percent of $\mathrm{CD} 4^{+} \mathrm{T}$ cells from offspring of OVA-fed DO11.10 dams (transgenic mice bearing OVA-specific T-cell receptor) proceeded into $\mathrm{S}$ phase 72 -h after in vitro stimulation with OVA. In contrast, the majority of $\mathrm{CD} 4^{+} \mathrm{T}$ cells from offspring of unexposed DO11.10 dams were arrested in $G_{0} / G_{1}$ phase, suggesting that offspring T-cells are primed in utero by oral administration of dams with allergen. It is noteworthy that OVA was undetectable in amniotic fluid, placental serum, or breast milk from OVA-fed dams during pregnancy. In contrast, when dams were orally administered during the first week of breastfeeding, OVA was detectable in milk from OVA-fed dams in proportion to the dam's intake dose. Levels of maternal allergen-specific Igs were not examined in this study. These results suggest that oral exposure of dams to low-dose allergen during pregnancy may result in T-cell priming to allergen in utero, although whether maternal Igs are involved in this setting is not clear. Intranasal exposure of WT dams with OVA before conception resulted in the induction of tolerance in offspring toward allergic airway inflammation as well as allergen-specific Th2 responses following i.p. sensitization with OVA and alum and intranasal OVA challenge (100). Interestingly, the preventive effects against allergic inflammation were completely abolished in B-cell deficient $\mu$ MT dams. The study proposes that OVA-IgG1IC bind to $\mathrm{CD} 16$ and $\mathrm{CD} 32 \mathrm{Fc} \gamma$ receptors $(\mathrm{F} \gamma \mathrm{R})$ on dendritic cells (DCs) and promote an efficient allergen-priming by DCs to promote differentiation of forkhead box $\mathrm{p} 3$ (Foxp3) ${ }^{+}$regulatory $\mathrm{T}$ cells (Treg) in utero, suggesting a role of allergen-IgG-IC in the induction of neonatal tolerance during pregnancy. More recent study demonstrated that anti-IgE antibody treatment of pregnant dams prevents allergen-specific IgE production in offspring following allergen sensitization (120).

Effects of maternal IFN- $\gamma$ on development of offspring asthma were investigated in dams treated with IFN- $\gamma$ (101). Dams were i.p. injected with IFN- $\gamma$ during pregnancy, then offspring were fostered after birth and nursed by normal dams untreated with IFN- $\gamma$ (IFN/Nor). Conversely, offspring of naïve dams were fostered and nursed by dams treated with IFN$\gamma$ (Nor/IFN) or untreated normal dams (Nor/Nor). Following OVA inhalation, both IFN/Nor and Nor/IFN offspring showed 
TABLE 2 | Maternal protective and risk factors for offspring allergy in human studies.

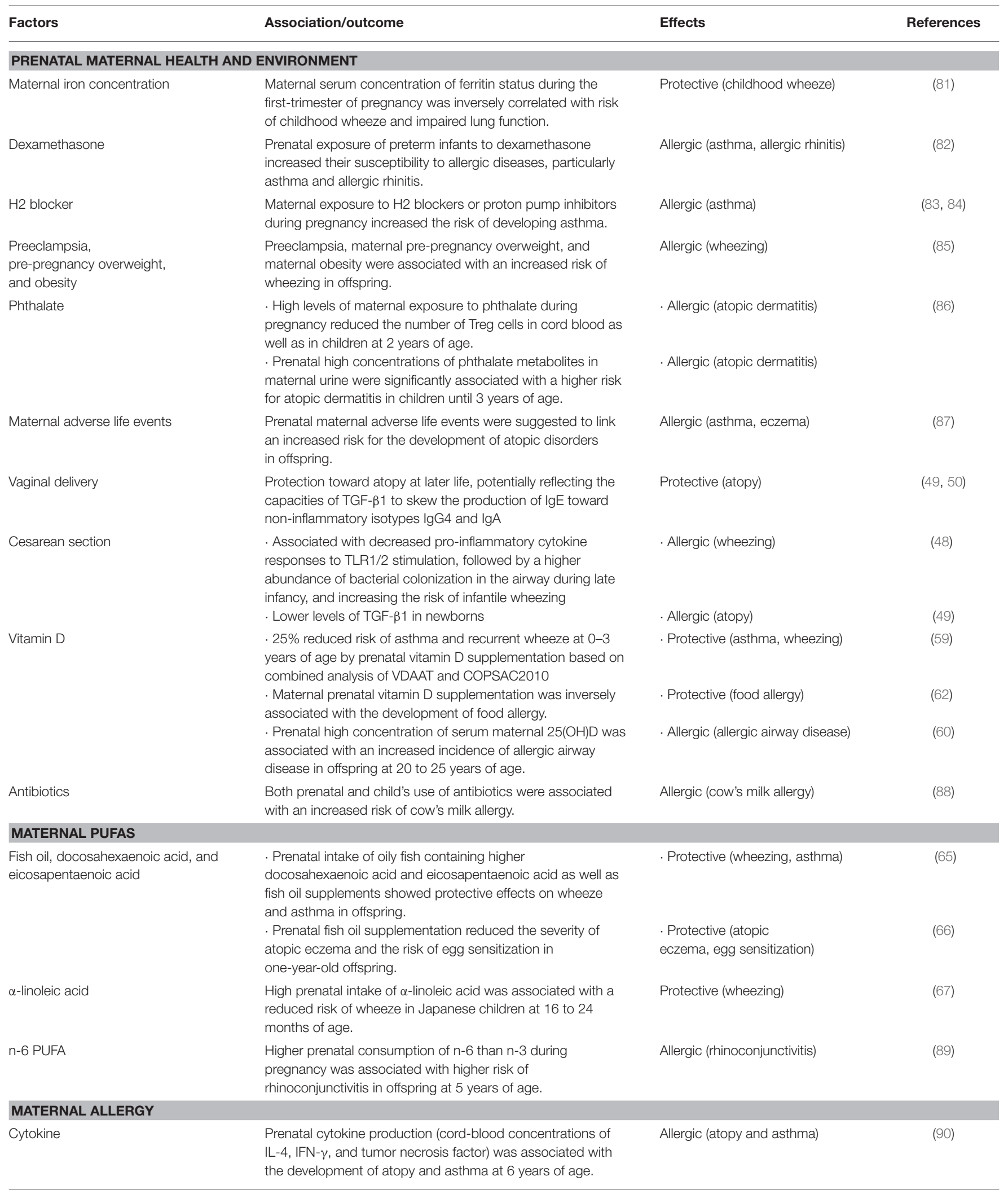


TABLE 2 | Continued

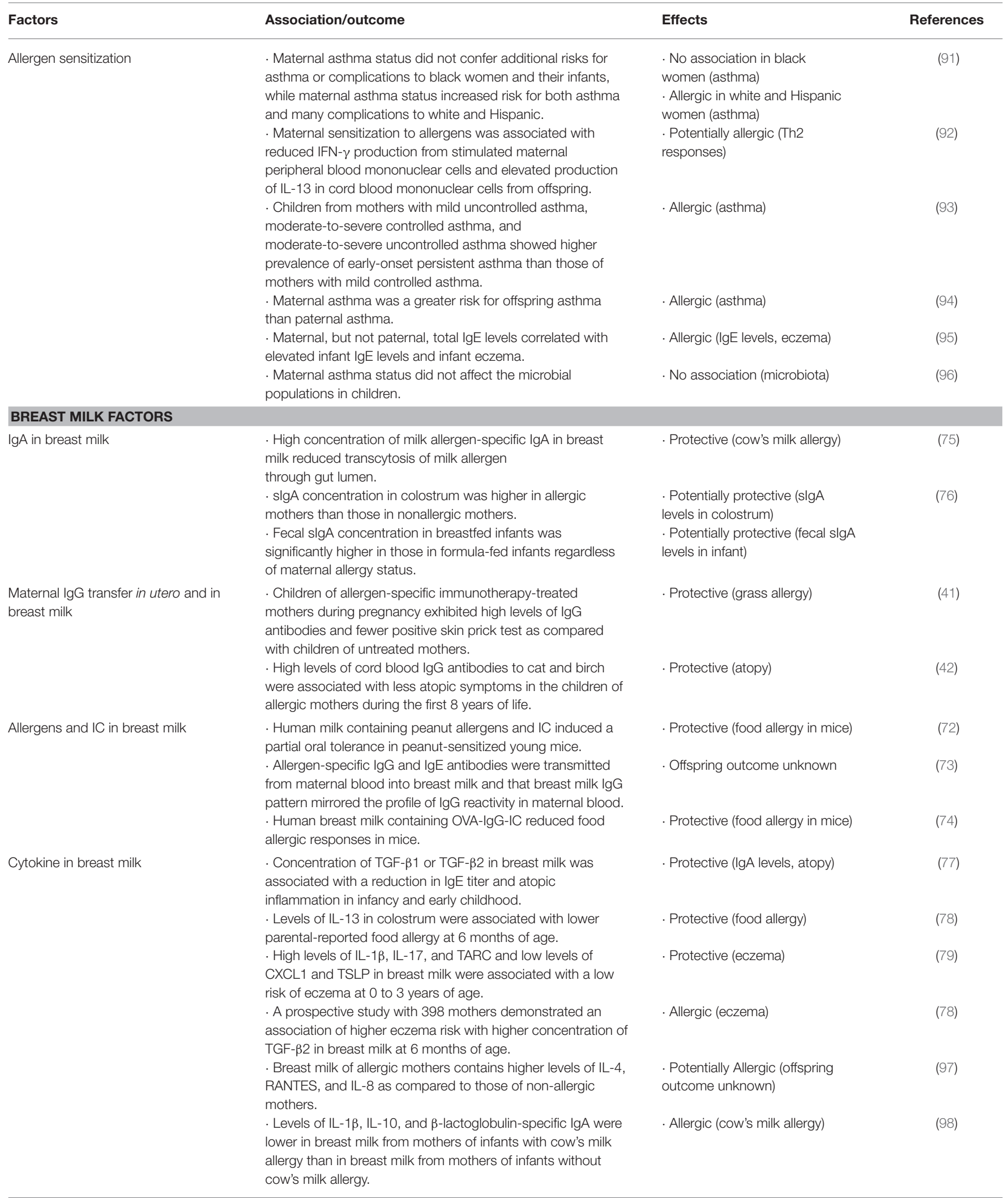

25(OH)D, 25-hydroxyvitamin D; COPSAC, Copenhagen Prospective Studies on Asthma in Childhood; IC, immunecomplex; IFN, interferon; Ig, immunoglobulin; IL, interleukin; OVA, ovalbumin; PUFAs, polyunsaturated fatty acids; RANTES, regulated on activation, normal T cell expressed and secreted; slgA, secretary IgA; TARK, C-C motif Chemokine ligand (CCL) 17; TGF- $\beta$, tumor growth factor $\beta$; TLR, toll-like receptor; Treg, regulatory T cell; TSLP, thymic stromal lymphopoietin; VDAART, vitamin D antenatal asthma reduction trial. 
TABLE 3 | Maternal protective and risk factors for offspring allergy in mouse models.

\begin{tabular}{|c|c|c|c|c|c|}
\hline Responsible factors & Strains & Treatment to dam & Dose/timing & Effects & References \\
\hline \multicolumn{6}{|l|}{ IN UTERO } \\
\hline Allergen & $\mathrm{BALB} / \mathrm{c}, \mathrm{DO} 11.10$ & - Oral administration & $\begin{array}{l}\cdot \text { High-dose OVA }(9 \mathrm{mg}) \text { during } \\
\text { the first week of pregnancy } \\
\cdot \text { Low-dose OVA }(1.5 \mathrm{mg}) \text { during } \\
\text { pregnancy } \\
\cdot \text { Low-dose OVA }(1.5 \mathrm{mg}) \\
\text { during pregnancy }\end{array}$ & $\begin{array}{l}\text { Suppression of OVA-specific lgE levels in } \\
\text { 3-day-old, but not in 25-day-old, BALB/c } \\
\text { offspring } \\
\text { - Sustained inhibition of OVA-specific lgE levels } \\
\text { both in 3- and } 25 \text {-day-old BALB/c offspring } \\
\text { - In utero priming of offspring DO11.10-derived } \\
\text { T cells }\end{array}$ & (99) \\
\hline $\begin{array}{l}\text { B cells } \\
\text {. Allergen-IgG-IC }\end{array}$ & $\begin{array}{l}\text { C57BL/6, Mature } \\
\text { B-cell-deficient } \mu \mathrm{MT}\end{array}$ & Intranasal exposure & $500 \mu \mathrm{g}$ OVA before conception & $\begin{array}{l}\text { - Induction of tolerance in C57BL/6 offspring } \\
\text { against allergic airway inflammation } \\
\text { - Abolished preventive effects against allergic } \\
\text { airway inflammation in } \mu \mathrm{MT} \\
\text { - OVA-IgG1-IC bound to Fc } \gamma \text { R and promoted } \\
\text { differentiation of Foxp3 } 3^{+} \text {Treg. }\end{array}$ & $(100)$ \\
\hline $\begin{array}{l}\text { Maternal IgG and } \\
\text { offspring IFN- } \gamma\end{array}$ & $\begin{array}{l}\text { BALB/c, C57BL/6J, } \\
\text { FcRn- } \\
\text { deficient B6.129X1- } \\
\text { Fcgrttm1Dcr }\end{array}$ & Oral administration & 100 mg OVA before conception & $\begin{array}{l}\text { In utero IgG transfer decreased the disease } \\
\text { severity in BALB/c offspring. } \\
\text { Offspring of FcRn-deficient dam nursed by } \\
\text { OVA-fed C57BL/ } 6 \text { WT dams showed protective } \\
\text { effects against OVA-induced asthma-like } \\
\text { symptom. } \\
\text { - Anti-IFN- } \gamma \text { treatment of offspring during } \\
\text { sensitization and challenge with allergen abolished } \\
\text { the protection. }\end{array}$ & (102) \\
\hline $\begin{array}{l}\text { Maternal TLR signaling } \\
\text { and offspring IFN }-\gamma\end{array}$ & $\begin{array}{l}\text { BALB/c, C57BL/6 } \\
\text { T/r2/3/4/7/9-/- }\end{array}$ & $\begin{array}{l}\text { Intranasal applications } \\
\text { of freeze-dried A. Iwoffii } \\
\text { F78 suspended in PBS }\end{array}$ & $\begin{array}{l}10^{8} \mathrm{CFU} \text { of } A \text {. Iwoffii F78 during } \\
\text { i prenatal period }\end{array}$ & $\begin{array}{l}\text { - IFN- } \gamma \text {-dependent prevention of experimental } \\
\text { asthma in BALB/c offspring } \\
\text { - A significant reduction in acetylation levels of } \\
\text { histone } 4 \text { of the } / / 4 \text { promoter after OVA challenge } \\
\text { The preventive effect was completely abolished } \\
\text { in heterozygous offspring of } A \text {. Iwoffii F78-treated } \\
\text { T/r2/3/4/7/9-/- dam. }\end{array}$ & $(103,104)$ \\
\hline $\begin{array}{l}\text { Short-chain fatty acid, } \\
\text { especially acetate }\end{array}$ & C57BL/6 & $\begin{array}{l}\text { Fed with high-fiber diet } \\
\text { or drinking water with } \\
\text { acetate or propionate }\end{array}$ & $\begin{array}{l}\text { High-fiber diet: SF11-025 } \\
.200 \mathrm{mM} \text { acetate or propionate }\end{array}$ & $\begin{array}{l}\text { Offspring of dams fed high-fiber diet or acetate } \\
\text { failed to develop allergic airway disease. } \\
\text { - Dams showed significant changes in microbiota } \\
\text { composition, which was accompanied by an } \\
\text { increase in high-acetate-producing Bacteroidetes } \\
\text { and short-chain fatty acids in their feces } \\
\text { and serum. }\end{array}$ & (106) \\
\hline $\begin{array}{l}\text { IL-4 signaling in } \\
\text { asthmatic dams }\end{array}$ & $\mathrm{BALB} / \mathrm{c}$ & $\begin{array}{l}\text { Immunized with } \\
\text { OVA/alum and exposed } \\
\text { to OVA aerosol }\end{array}$ & $\begin{array}{l}\text { Preconceptionally immunized } \\
\text { with } 5 \mu \mathrm{g} \text { OVA } 1 \mathrm{mg} \text { alum and } \\
\text { exposed to } 3 \%(\mathrm{w} / \mathrm{v} \text { ) OVA } \\
\text { aerosol during pregnancy }\end{array}$ & $\begin{array}{l}\text { Offspring of OVA-dams, but not of unsensitized } \\
\text { dams, exhibited allergic airway inflammation in } \\
\text { response to suboptimal sensitization with } \\
\text { OVA valum and OVA aerosol. } \\
\text { - This model of maternal transmission of asthma } \\
\text { susceptibility to offspring was } \\
\text { not allergen-specific. }\end{array}$ & $(107)$ \\
\hline $\begin{array}{l}\text { Maternal } \\
\text { allergen-specific T cells }\end{array}$ & $B A L B / c$ & $\begin{array}{l}\text { Adoptive transfer of } \\
\text { DO11.10-derived T } \\
\text { cells to naive dams }\end{array}$ & $\begin{array}{l}5 \times 10^{6} \mathrm{DO} 11.10 \mathrm{~T} \text { cells/mouse } \\
\text { i.p. at } 3 \text { days before mating }\end{array}$ & $\begin{array}{l}\text { - Higher responsiveness of offspring to suboptimal } \\
\text { challenge of OVA } \\
\text { - Donor T cells were identified in spleen and } \\
\text { placenta of the recipient female dams but were } \\
\text { not detectable in fetal tissues. }\end{array}$ & (108) \\
\hline
\end{tabular}


TABLE 3 | Continued

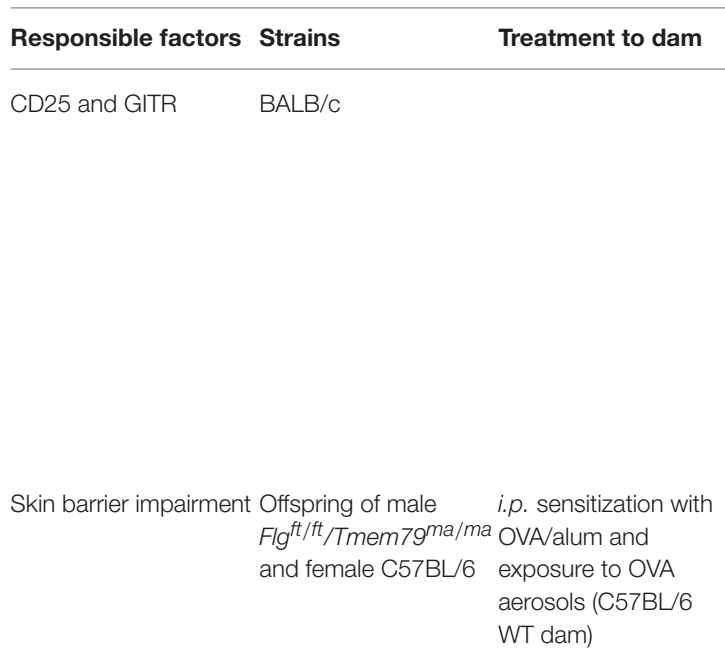

\section{BREASTFEEDING}

Allergen in breast milk BALB/C

$\begin{array}{ll}\text { Airborne } & \begin{array}{l}0.5 \% \text { OVA every other day } \\ \text { during lactation }\end{array}\end{array}$

Effects

- Depletion of CD25 $5^{\text {high }} \mathrm{T}$ cell . Increased susceptibility to allergic airway population in 4-day-old newborn inflammation in normal offspring mice before induction of airway . Substantial reduction in asthma symptoms in inflammation - Anti-GITR antibody treatment . Significant attenuation of the susceptibilities to before induction of airway inflammation with suboptimal sensitization protocol - Anti-GITR antibody treatment after induction of airway inflammation

$5 \mu \mathrm{g}$ OVA $1 \mathrm{mg}$ alum and exposed to $3 \%(\mathrm{~W} / \mathrm{V})$ OVA aerosol before mating with unsensitized flaky tail male mice . Associated with higher levels of transcripts for CCL11, TSLP and IL-33 in skin, and TSLP in jejunum allergic airway inflammation in offspring of both naïve and asthmatic dams

. Enhanced asthma-like allergic inflammation in normal offspring

- Slight deterioration of allergic airway inflammation in the offspring of asthmatic dams - Increase in food allergen sensitization, serum mMCP1, and anaphylaxis to food allergen sensitization
References

(109)

- Intact OVA and its degraded products were detectable in breast milk.

- Offspring of OVA-exposed dams showed a significant protection against allergic airway inflammation, production of antigen-specific lgE, IgG1, and IgA antibodies, allergen-specific secretion of Th2 cytokines and IL-10 compared to offspring of unexposed dams.

- The decrease in the disease susceptibility in offspring was independent on maternal lgs or IL-10.

Oral administration

$2 \mathrm{mg}$ OVA three times a week in . Oral tolerance induction in offspring were the first, second, and third week completely abolished in those nursed by dams of or throughout breastfeeding treated with anti-TGF- $\beta$ monoclonal antibodies. - Oral tolerance induction in offspring of OVA-fed dams was insufficient in 1-week-old neonates, accompanied by a reduction in gut barrier, retinaldehyde dehydrogenase expression by mesenteric lymph node CD103 ${ }^{+}$neonatal DCs. - One-week-old neonates were refractory to oral tolerance elicited by maternal allergen transfer via milk due to a physiological vitamin A deficiency. - Vitamin A supplementation rescued these neonatal defects and induced efficient tolerance in 1-week-old mice.

- Oral tolerance was also dependent on offspring IFN- $\gamma$.

- Induced a long-lasting allergen-specific protection from asthma.

- OVAvalum i.p.

. $10 \mu \mathrm{g}$ OVAV2 mg alum, preconceptionally

- Exposure of OVA . $0.3 \%$ OVA during breastfeeding was associated with the differentiation of Foxp3

Treg cells in offspring.

- OVA-specific D011.10-derived T cells

co-cultured with bone marrow-derived DCs proliferated and upregulated Foxp3 expression in vitro in the presence of breast milk from OVA-exposed dams or . OVA-IgG-IC purified from breast milk.

- OVA-IgG-IC induced the proliferation of D011.10-derived T cells at least 100-fold more efficiently than OVA alone.

- Milk IC-mediated tolerance was more profound than the tolerance induced by milk-borne free allergen and did not require TGF- $\beta$, IgA, or FcyRllb. 
TABLE 3 | Continued

\begin{tabular}{|c|c|c|c|}
\hline Responsible factors & Strains & Treatment to dam & Dose/timing \\
\hline $\begin{array}{l}\text { IgG1 and FCRn } \\
\text { in offspring }\end{array}$ & $\begin{array}{l}\text { B-cell deficient } \\
\text { lgh6 } 6^{\operatorname{tm} 1 C g n}, \\
\text { C57BL6/J, } \\
\text { FCRn-deficient } \\
\text { Fcgrt }^{-/-}\end{array}$ & $\begin{array}{l}\text { - i.p. injection } \\
\text { with OVA/alum } \\
\text {. OVA aerosol }\end{array}$ & $\begin{array}{l}\cdot 25 \text { or } 8 \mu \mathrm{g} \text { OVA } 2 \text { mg alum } \\
\text { before mating } \\
\cdot 1 \% \text { OVA dairy before mating } \\
\text { and during embryonic days } \\
11-17 \text { of pregnancy }\end{array}$ \\
\hline
\end{tabular}

\begin{tabular}{|c|c|c|}
\hline $\begin{array}{l}\text { Amount of allergen } \\
\text { directly taken by infant }\end{array}$ & $\mathrm{C} 3 \mathrm{H} / \mathrm{HeJ}$ & $\begin{array}{l}\text { Peanut exposure } \\
\text { by gavage }\end{array}$ \\
\hline
\end{tabular}

by gavage

Oral peanut/CT exposure by gavage

exposure during

pregnancy

and lactation
$\mathrm{C} 3 \mathrm{H} / \mathrm{HeJ}$

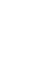

Allergens and allergen- BALB/C specific immunoglobulins .i.p. injection of OVAvalum

- Oral administration of OVA drinking water during breastfeeding for 2 weeks at 2-week interval periconceptionally . $1 \%$ OVA in
Effects

- Offspring nursed by B-cell deficient $\operatorname{lgh} 6^{\mathrm{tm} 1 \mathrm{Cgn}}$ mice failed to show protection against

OVA-specific IgE production and OVA-induced allergic airway inflammation.

. Fcgrt ${ }^{-/}$- offspring nursed by OVA-sensitized WT dams exhibited 1/1,000 to 1/10,000 lower levels of maternal OVA-specific IgG1 than those in similarly nursed FCgrt ${ }^{+/-}$or WT offspring and failed to show protection against OVA-specific lgE production and allergic airway inflammation.

$10 \mathrm{mg} /$ mouse ground peanut . No influence of maternal peanuts exposure three times a week for 4 weeks during pregnancy on offspring peanut prior conception or sensitization preconceptionally and during pregnancy and breastfeeding

- Enhanced peanut-allergen uptake by CD11c ${ }^{+}$

DCs in Peyer's patch subepithelial dome in coadministration of peanut extract with breast milk from allergic dams as compared to coadministration of that from naïve dams - Oral administration of small dose $(1 \mathrm{mg})$ of peanut extract to offspring with breast milk from sensitized or naïve dams during post-weaning period failed to enhance the induction of tolerance compared to those orally administered peanut extract alone in offspring.

- Offspring of dams preconceptionally sensitized

. $10 \mathrm{mg} / \mathrm{mouse}$ with peanut/CT exhibited maternal lgG1-mediated weekly and peanut exposure (50 anaphylaxis in response to oral peanut challenge. $\mathrm{mg} / \mathrm{mouse}$ ) preconceptionally

\section{. $10 \mathrm{mg} / \mathrm{mouse}$}

Offspring were protected from anaphylaxis ground peanut/20 $\mu \mathrm{g} /$ mouse CT following first peanut challenge as well as active preconceptionally and during pregnancy and breastfeeding peanut/CT sensitization and oral peanut challenge. . $50 \mu \mathrm{g}$ OVA $1.3 \mathrm{mg}$ alum twice

\section{Oral TGF- $\beta$} supplementation after weaning BALB/c i.p. injection of OVAvalum

- Oral administration of OVA
. $10 \mu \mathrm{g}$ OVA $2 \mathrm{mg}$ alum. twice at 1 -week interval at 2 days before mating . $2 \mathrm{mg}$ OVA by gavage three times a week during lactation
- Offspring of OVA-sensitized and challenged dams showed the most significant reduction in food allergic responses, as indicated by a decrease in levels of diarrhea occurrence, OVA-specific IgE, $1 / 4$ mRNA expression, and numbers of mucosal mast cells in proximal colon compared to those in offspring from naiive dams. . Offspring from dams unsensitized and challenged with OVA exhibited a partial but a significant reduction in food allergic responses compared to those from naiive dams.

- Offspring from OVA-sensitized dams without oral OVA challenge showed comparable food allergic responses to offspring of naïve dams.

- Offspring of naïve dams nursed by

OVA-sensitized dams showed a significant reduction in levels of diarrhea score, serum mMCP1, and OVA-specific IgE antibodies compared to naiive offspring nursed by naive dams.

- Breastfeeding by OVA-dams decreased the frequencies of allergic diarrhea in response to multiple oral OVA challenges in 6-week-old, but not in 13-week-old offspring.

- Supplementation with TGF- $\beta$ after weaning till 12-week prolonged protection against diarrhea and improved gut barrier in 13-week-old mice breastfed by OVA-dams.
References

$(113,114)$ 
TABLE 3 | Continued

\begin{tabular}{|c|c|c|c|c|c|}
\hline Responsible factors & Strains & Treatment to dam & Dose/timing & Effects & References \\
\hline $\begin{array}{l}\text { Maternal OVA IgG-IC } \\
\text { and offspring FcRn }\end{array}$ & $\begin{array}{l}\text { BALB/c, } \\
\text { FcRn-deficient } \\
\text { Fcgrt }^{-/-}\end{array}$ & $\begin{array}{l}\text { - Epicutaneous } \\
\text { sensitization } \\
\text {-i.p. injection } \\
\text { of OVA-IgG1-IC }\end{array}$ & $\begin{array}{l}\text { - } 100 \mu \mathrm{g} \text { OVA } \\
\text { preconceptionally and during } \\
\text { pregnancy and breastfeeding } \\
\text { - } 100 \mu \mathrm{g} \\
\text { OVA-IgG1-IC once weekly for } 3 \\
\text { weeks during breastfeeding }\end{array}$ & $\begin{array}{l}\text { - Maternal allergen sensitization through skin } \\
\text { prevented food anaphylaxis, allergen-specific IgE } \\
\text { production, serum IL-4, serum mMCP1, and } \\
\text { intestinal mast cell expansion in BALB/c offspring. } \\
\text { - The protective effects of food allergy by } \\
\text { OVA-sensitized dam were abolished in Fcgrt } \\
\text { - Offspring of naïve dams supplemented with } \\
\text { OVA-IgG1-IC showed increase of serum } \\
\text { OVA-IgG1-IC levels, OVA-specific Treg in } \\
\text { mesenteric lymph node at weaning, and } \\
\text { protection against food allergy. }\end{array}$ & (74) \\
\hline $\begin{array}{l}\text { Th2-biased } \\
\text { epigenetic alteration }\end{array}$ & $\mathrm{C} 3 \mathrm{H} / \mathrm{HeJ}$ & Intragastric & $\begin{array}{l}10 \text { mg peanut/20 } \mu \mathrm{g} \text { CT weekly } \\
\text { for } 5 \text { weeks and } 200 \text { mg peanut } \\
\text { at } 6 \text { weeks before conception }\end{array}$ & $\begin{array}{l}\text { Offspring of dams sensitized and challenged with } \\
\text { peanut exhibited increased food allergic } \\
\text { responses following suboptimal dose of oral } \\
\text { peanut/CT sensitization and peanut challenge, } \\
\text { associated with hypomethylation at CpG sites of } \\
\text { //4 gene promoter. }\end{array}$ & $(118)$ \\
\hline
\end{tabular}

A. Iwoffii, Acinetobacter Iwoffii; CCL, C-C motif chemokine ligand; CFU, colony forming unit; CT, cholera toxin; DC, dendritic cell; FCyR, FC gamma receptor; FCRn, neonatal FC receptor; Foxp3, forkhead box p3; GITR, glucocorticoid-induced tumor necrosis factor receptor-family related receptor; IC, immunecomplex; IFN, interferon; Ig, immunoglobulin; IL, interleukin;

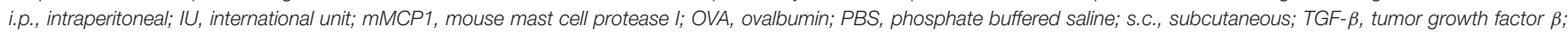
Th, helper T cell; TLR, toll-like receptor; Treg, regulatory T cell; TSLP, thymic stromal lymphopoietin; WT, wild type.

reduced numbers of eosinophils in bronchoalveolar lavage fluid, but only IFN/Nor offspring showed almost normal lung histology. IFN/Nor offspring also showed amelioration of passive cutaneous anaphylaxis. These results suggest that maternal IFN$\gamma$ induces stronger protective effects when prenatally transferred in utero than when postnatally transferred via breast milk against allergic airway inflammation in offspring.

The importance of IFN- $\gamma$ in the protection of offspring against allergic inflammation was proposed in another study that demonstrated that transfer of maternal IgG to the offspring induced offspring tolerance against asthma-like phenotype (102). Offspring of BALB/c WT dams orally administered OVA before conception were protected from development of allergic airway inflammation induced by i.p. sensitization and intranasal challenge with OVA. Offspring of OVA-fed dams nursed by naïve dams were also protected, suggesting the role of in utero IgG transfer in decreasing the disease severity in offspring. Offspring of FcRn-deficient dams, unable to transport IgG through placenta, nursed by OVA-fed WT dams showed protective effects against OVA-induced asthma-like symptoms, indicating the contribution of IgG transfer also via breast milk to protection of offspring. Anti-IFN- $\gamma$ treatment of offspring during sensitization and challenge with allergen abolished the protection. This study suggests that this maternal IgG-mediated suppression of allergic airway inflammation is dependent on offspring IFN- $\gamma$, indicating the synergistic effects of maternal-offspring factors in shaping neonatal responses to allergic diseases. How OVA administration to dams through usually tolerizing oral route results in generation of allergen-specific IgG was not clear in this study.

Exposure of dams with farm-derived, gram-negative bacterium Acinetobacter lwoffii F78 during prenatal period resulted in prevention of experimental asthma in their offspring, which was dependent on maternal TLR signaling (103). The follow-up study demonstrated that the preventive effects were dependent on offspring IFN- $\gamma$ (104) and that offspring from dams exposed to $A$. lwoffii F78 showed a significant reduction in acetylation level of histone 4 , a marker for an open chromatin structure, of the Il4 promoter after OVA challenge. Since bacteria were not detectable in offspring, these data imply that prenatal exposure of dams to certain microbiota exerts protective effects in offspring against allergic responses through epigenetic regulation of cytokines.

One of the earlier studies compared the effects of maternal factors from dams with Th1 immune responses vs. dams with Th2 immune responses on allergic airway inflammation in offspring. Dams were preconceptionally immunized with OVA and complete Freund's adjuvant subcutaneously followed by a booster of OVA plus incomplete Freunt's adjuvant i.p. to induce Th1-biased immunity, or immunized with OVA and alum i.p. to induce Th2-biased immunity. Immunized dams were exposed to OVA aerosol before pregnancy then received recall OVA aerosol during pregnancy. Offspring of dams with Th1biased immunity showed reduced levels of OVA-specific IgE and airway eosinophilia in response to immunization with OVA and alum (OVA/alum) and challenge with OVA aerosol compared with offspring of dams with Th2-biased immunity or naïve dams. Offspring of dams with Th1-biased immunity to bovine serum albumin did not show protection against development of OVA-specific IgE or OVA-induced airway inflammation, suggesting that the suppression of allergic airway inflammation in offspring from Th1-biased dams is antigen-specific. Although offspring of Th2-biased dams failed to show protection against OVA-induced airway inflammation, these offspring showed a trend toward lower levels of OVA-specific IgE as compared to offspring of naive dams (105). As Th1-biased dams were challenged with allergen before and during pregnancy but not during breastfeeding, these data suggest that maternal transfer of allergen and allergen-specific Igs in utero in the context of Th1 
immune responses results in the resistance of offspring to allergic airway inflammation. It is possible that allergen-specific Igs continued to be transferred from Th1-biased dams to offspring through breast milk, and that these antibodies also contribute to prevent allergic inflammation in offspring, as shown in their follow-up study (113) as discussed in section Breastfeeding in Mouse Studies for maternal protective influences.

\section{Microbiota}

Animal models have evidently shown that the intestinal dysbiosis confers susceptibility to food allergy (121) and that certain bacteria such as Clostridia species that are protective from food allergy (122-124). Germ-free mice colonized with feces from healthy infants, but not from cow's milk allergic infants, protected against anaphylactic responses to a cow's milk allergen and that Anaerostipes caccae, a non-spore-forming, butyrate producing Clostridial species was critical for the protection against food allergy (123). Bacteriotherapy with Clostridiales species, impacted by dysbiosis in human infants with food allergy, suppressed food allergy in mice via MyD88/ROR- $\gamma \mathrm{t}^{+}$ Treg cell pathway (124), indicating that microbiota critically regulate food allergy. A study reported that progeny of dams fed with high-fiber diet during pregnancy showed suppression of allergic airway inflammation (106). Dams fed with highfiber diet showed significant changes in microbiota composition, which is accompanied by an increase in high-acetate-producing Bacteroidetes and short-chain fatty acids in their feces and serum. The increase in short-chain fatty acid, especially acetate, in dams during pregnancy induced Treg in offspring mediated by enhancing acetylation of Foxp3 promoter through inhibition of histone deacetylase 9 in utero. These reports suggest that maternal microbiota influences the susceptibility of offspring to allergies through epigenetic modification in utero.

Collectively, these observations indicate that maternal environment and maternal factors directly or indirectly affect offspring immune system during pregnancy likely contribute to the induction of tolerance. Potential preventive effects of in utero factors on offspring food allergy have been much less studied as compared to asthma models. Our study shows that offspring born from allergen-sensitized dams nursed by naïve dams exhibited a trend toward protection against food allergy (74), suggesting that in utero factors such as IC contribute to the reduced disease susceptibility, however, breastfeeding is essential to induce optimal tolerance induction. Investigations of the timing (prenatal, postnatal, or throughout), factors (allergen, Igs, IC, cytokine milieu, and microbiota), and dose of those factors in the interplay of pathogenic vs. regulatory responses in allergic diseases in offspring will be needed to understand this complex relationship.

\section{Breastfeeding}

In mouse studies, breastfeeding has been shown to be critical in the induction of tolerance toward allergic sensitization in postnatal period $(74,119)$. Similar to in utero period, maternal factors such as allergen, Igs, IC, and TGF- $\beta$ in breast milk induce allergen-specific tolerance against allergic sensitization and inflammation. Maternal immune cells are present in breast milk and are transferred into offspring tissues (125). These factors may act individually or in synergy to prevent development of allergy in offspring through multiple mechanisms.

\section{Allergen, allergen-specific Igs, and cytokine}

Tolerance induction by allergen in milk has been the subject of many studies that use experimental asthma models. Aerosol OVA exposure of WT dams during lactation resulted in an allergen transfer to offspring via milk and the induction of allergenspecific tolerance toward allergic airway inflammation (111). Intact OVA and its degraded products were detected in breast milk from OVA-exposed dams during breastfeeding with the concentration in the similar range as those in human breast milk after consumption of egg or cow's milk $(180 \pm 20 \mathrm{ng} / \mathrm{ml})$ (111). Offspring of OVA-exposed dams showed a significant protection against allergic airway inflammation, production of antigen-specific IgE, IgG1, and IgA antibodies, allergen-specific secretion of Th2 cytokines and IL-10 compared to offspring of unexposed dams. The decrease in the disease susceptibility in offspring was independent on maternal Igs or IL-10. Given that dams were not sensitized with allergen, i.e., in the absence of maternal allergen-specific Igs, it is not surprising that maternal Igs were not required for the induction of tolerance in this system. In contrast, the suppressive effects in offspring were completely abolished in those nursed by dams treated with anti-TGF- $\beta$ monoclonal antibodies, indicating that maternal TGF- $\beta$ during breastfeeding are required for the induction of tolerance. In mice, 1 -week-old neonates were refractory to oral tolerance induced by maternal allergen transfer through milk due to a physiological vitamin A deficiency (112). Unsensitized dams were given OVA in the first, second, or third week of or throughout lactation and tolerance induction in offspring to OVA-induced allergic airway inflammation was examined. Oral tolerance induction in offspring of OVA-fed dams was insufficient in 1week-old neonates, accompanied by a reduction in gut barrier, the expression of retinaldehyde dehydrogenase by mesenteric lymph node $\mathrm{CD}_{103^{+}}$neonatal DCs leading to inefficient T-cell priming, and serum retinol levels as compared to those in adult mice. Supplementation with vitamin A rescued these defects in neonates and induced efficient tolerance in 1-week-old mice. Oral tolerance was also dependent on offspring IFN- $\gamma$. These data may suggest maternal allergen transfer through milk together with vitamin A supplementation as possible interventions for prevention of allergy in the neonates (112). The same group next demonstrated that breastfeeding by preconceptionally sensitized WT dams with OVA/alum i.p. exposed to OVA aerosols during breastfeeding induced a long-lasting allergen-specific protection toward asthma. Dams sensitized and exposed to OVA exhibited OVA-IgG-IC in breast milk (18). Eighty-five percent of OVA in breast milk formed OVA-IgG-IC (18). OVA-IgG-IC transferred into offspring by FcRn was associated with the differentiation of Foxp $^{+}$Treg cells in offspring. OVA-specific DO11.10-derived $\mathrm{T}$ cells co-cultured with bone marrow-derived DCs proliferated and upregulated Foxp3 expression in vitro with breast milk from OVA-exposed dams or OVA-IgG-IC purified from breast milk. OVA-IgG-IC promoted the proliferation of DO11.10-derived T cells at least 100-fold more efficiently than OVA alone. Milk 
IC-mediated tolerance was more profound than the tolerance induced by milk-borne free allergen and did not require TGF$\beta$, IgA, or Fc $\gamma$ RIIb (18). These studies suggest that milk-borne allergen protects offspring against asthma, and allergen as IC induces more efficient tolerance in neonates independently of TGF- $\beta$. Consistently, earlier studies indicated that when dams are sensitized with allergen, breast milk-induced tolerance in offspring require maternal B cell and offspring FcRn $(105,113$, 114). Offspring nursed by B-cell deficient $\operatorname{Igh} 6^{\mathrm{tm} 1 \operatorname{cgn}}$ mice failed to show protection against OVA-specific IgE production and OVAinduced allergic airway inflammation (113). The same group demonstrated that $\mathrm{FcRn}^{-/}$offspring nursed by OVA-sensitized WT dams exhibited $1 / 1,000$ to $1 / 10,000$ lower levels of maternal OVA-specific IgG1 than those in similarly nursed $\mathrm{FcRn}^{+/-}$ or WT offspring (114) and failed to show protection against OVA-specific IgE production and allergic airway inflammation. Collectively, these studies imply that allergen, IgG, and IC in breast milk as well as offspring FcRn are crucial for the induction of tolerance in allergic airway inflammation in offspring.

Regarding food allergy, maternal effects on protection of offspring toward food allergy were investigated in several mouse models. $\mathrm{C} 3 \mathrm{H} / \mathrm{HeJ}$ dams (lack a functional TLR4 that recognizes lipopolysaccharide) preconceptionally exposed to peanut exhibited variable levels of maternal Igs in sera and breast milk, though, maternal preconceptional peanut exposure or also during pregnancy and breastfeeding showed no influence on offspring peanut allergy induced by oral immunization with peanut and cholera toxin (CT) and oral plus i.p. peanut challenge (115). The efficacy of a direct oral tolerance induction in offspring was similar in offspring of dams exposed to peanut and in offspring of dams that did not consume peanut. Oral administration of crude peanut extract together with breast milk of peanut exposed dams onto 5-week-old offspring induced an enhanced peanut-allergen uptake by $\mathrm{CD}_{11 \mathrm{c}^{+}}$DCs in Peyer's patch subepithelial dome as compared to coadministration of peanut extract with breast milk from naïve dams. However, oral administration of small dose $(1 \mathrm{mg})$ of peanut extract to offspring with breast milk from sensitized or naïve dams during postweaning period failed to enhance the induction of tolerance compared to those orally administered peanut extract alone in offspring. The authors suggest that dose of dietary allergens contained in breast milk may not be adequate to induce oral tolerance in their system. These results support the recent recommendations of no restrictions in diet for pregnant and breastfeeding mothers. Human milk containing peanut allergens induced partial protection in young mice following peanut sensitization (72), supporting a protective role of milk-born allergens in reducing offspring disease susceptibility. A more robust immunization of $\mathrm{C} 3 \mathrm{H} / \mathrm{HeJ}$ dams with oral peanut/CT and peanut exposure during pregnancy and lactation resulted in reduction of peanut allergy in offspring (17). Offspring of dams preconceptionally sensitized with peanut/CT exhibited maternal IgG1-mediated anaphylaxis following oral peanut challenge (first exposure). The anaphylaxis reaction was also dependent on platelet activation factor, but not IgE, as maternal IgE was undetectable in offspring. Remarkably, when sensitized dams received peanut/CT also during pregnancy and lactation, offspring showed protection against anaphylaxis following first peanut challenge as well as direct peanut/CT sensitization and oral peanut challenge. These findings suggest that maternal immune responses during pregnancy and lactation regulate the reduction of disease susceptibility in offspring.

Another study compared the susceptibility to food allergic responses of offspring from OVA/alum-sensitized vs. unsensitized dams with and without maternal oral OVA challenge during breastfeeding (116). Offspring of OVAsensitized and challenged dams showed the most significant reduction in food allergic responses, as indicated by decreased levels of diarrhea occurrence, OVA-specific IgE, Il4 mRNA expression, and numbers of mucosal mast cells in proximal colon compared to those in offspring from unsensitized and unchallenged (naïve) dams. Offspring from dams unsensitized and challenged with OVA exhibited a partial but a significant reduction in food allergic responses compared to those from naïve dams. Offspring from OVA-sensitized dams without oral OVA challenge showed comparable food allergic responses to offspring of naïve dams, indicating that there is no increase in food allergy susceptibility of offspring by in utero factors from allergen-sensitized dams in this system. OVA-specific IgG was detectable in breast milk and serum of offspring from OVAsensitized dams regardless of oral OVA challenge. OVA-specific IgA was detectable in breast milk only from OVA-sensitized and challenged dams. These results suggest that allergen-specific IgG and oral allergen exposure during breastfeeding resulting in production of allergen-specific IgA were required to induce an effective protection toward food allergy in offspring. These results suggest that even allergen-sensitized dams could have preventive effects on offspring allergies through breastfeeding. A recent study also demonstrated that allergen-sensitized dams protect offspring against food allergy through breast milk (117). Offspring of naive dams were fostered after birth by OVA-sensitized dams to avoid in utero effects then dams were orally challenged with OVA during breastfeeding. Offspring of naïve dams nursed by OVA-sensitized dams showed a significant reduction in levels of diarrhea score, serum mouse mast cell protease 1 (mMCP1), and OVA-specific IgE antibodies compared to naïve offspring nursed by naïve dams. The duration of oral tolerance elicited by breast milk toward food allergy was assessed in offspring of unsensitized dams nursed by dams preconceptionally immunized i.p. with OVA/alum then fed OVA during lactation. Breastfeeding by OVA-dams decreased the frequencies of allergic diarrhea in response to multiple oral OVA challenges in 6-week-old, but not in 13-week-old, offspring. TGF- $\beta$ supplementation after weaning till 12 -week prolonged protection toward diarrhea and enhanced gut barrier in 13-weekold mice nursed by OVA-dams. Lactation by allergen-sensitized dams together with offspring TGF- $\beta$ supplementation may maintain long-lasting prevention of allergic diarrhea (117).

Previous studies reported the involvement of allergenspecific IgG or IgG-IC from allergen-sensitized mothers in the protection of offspring against allergic airway inflammation via breastfeeding and FcRn $(18,102,114,126)$. In line with these reports, our recent study critically elucidated the fundamental mechanisms by which IC in breast milk regulates the induction 
of tolerance in offspring toward food allergy (74). Dams were epicutaneously sensitized with OVA or a clinically relevant allergen peanut followed by epicutaneous sensitization and oral challenge of their offspring with the same allergen. Maternal allergen sensitization through skin prevented food anaphylaxis, allergen-specific IgE production, serum IL-4, serum mMCP1, and intestinal mast cell expansion in offspring. The induction of tolerance was mediated by neonatal FcRn-dependent transfer of maternal OVA IgG-IC via milk and induction of allergen-specific Treg cells in offspring.

Neonatal tolerance was induced by breastfeeding by OVAsensitized dams or maternal supplementation with IgG-IC, suggesting an essential role of breast milk IgG-IC in the induction of tolerance. In addition to FcRn-dependent IgG-IC transfer, our work demonstrated that FcRn-dependent presentation of antigen by $\mathrm{CD} 11 \mathrm{c}^{+} \mathrm{DCs}$ was required for the induction of oral tolerance in offspring. Human breast milk from non-atopic mothers contained OVA-IgG-IC and was sufficient to induce tolerance in humanized FcRn mice, providing an important evidence for the potential relevance of our findings in human food allergy. Collectively, these findings demonstrate that interactions of offspring FcRn and maternal IgG-IC are critical in the induction of Treg cell responses that control food-specific tolerance in neonates, indicating the key role played by maternal allergenspecific Igs in milk in establishing tolerance that protects offspring from food allergy. These outcomes extend well beyond the previously defined roles of maternal antibodies and FcRn in stipulating passive immunity. Additionally, such food-specific IgG antibodies are induced during oral immunotherapy in humans and have been shown to act via Fc $\gamma$ RIIb to suppress IgE-mediated hypersensitivity (127). Strategies that modulate maternal IgG responses might be beneficial for the prevention of food allergy in offspring.

\section{Perspective}

In utero, the timing and dose of allergen exposure, allergenspecific Igs, and ICs along with the combination and balance of cytokine milieu and microbiota profile that reflective of maternal diet likely regulate the potential preventive effects in offspring toward allergies. Increasing evidences represent the importance of breastfeeding in the induction of neonatal tolerance, which is also modulated by maternal allergens, allergen-specific Igs, ICs, as well as cytokine profile (Table 3). Allergen alone in breast milk may induce offspring tolerance in synergy with TGF- $\beta$. Breastfeeding by allergen-specific IgG-positive dams protect offspring against allergic sensitization and allergic responses, particularly when dams are exposed to allergen during breastfeeding. The induction of tolerance in offspring by IgG or IgG-IC is more efficient than allergen alone and does not require TGF- $\beta$, although supplementation of TGF- $\beta$ may prolong the efficacy of IgG-IC-induced protection in offspring. In humans, increased allergy risk during early childhood indicates inadequate immune regulation in this life period. Both in prenatal and postnatal periods, it seems that maternal factors should interact with offspring immune system within specific time of window to successfully induce neonatal tolerance. More mechanistic studies are needed to elucidate the precise molecular mechanisms by which maternal factors modulate allergen-specific Treg cells and tolerance in offspring. For example, a particular DC subset and Fc receptors that are responsible for the induction of Treg cell responses remain elusive. An inhibitory Fc receptor Fc $\gamma$ RIIb and allergen-specific IgG have been shown to promote food tolerance $(127,128)$, but whether this receptor also plays a role in the context of maternal tolerance transfer needs to be examined. These issues will be the important subjects of future studies.

\section{MATERNAL INFLUENCES OVER OFFSPRING ALLERGY}

\section{Human Studies}

The early appearance of childhood allergies and the rise in their prevalence suggest that genetics and changes in earlylife exposures in utero may increase the predisposition. In this section, we focus on the potential maternal risk factors influence on development of offspring allergy, including genetic variance, diet, immunomodulating factors, as well as health status and environmental exposure.

\section{In utero Factors \\ Genetics}

A family history of allergy has been shown to be a risk factor for development of allergies in offspring (129). Common genetic factors driving allergic diseases including atopic dermatitis, asthma, and allergic rhinitis have been suggested $(130,131)$. Regarding food allergy, the first large-scale genome-wide association study (GWAS) identified 10 loci associating with allergic sensitization as indicated by the presence of allergenspecific IgE against common environmental allergens and selfreported allergic symptoms (132). The report suggests that allergic heritability is associated more with the severity of allergic symptoms and a general tendency for allergic sensitization (sensitization against any environmental allergen) than with sensitization against one specific allergen $(132,133)$. A recent GWAS in 2017 has identified five susceptibility loci for the disease; the clade B serpin (SERPINB) gene cluster, the cytokine gene cluster, the filaggrin gene, the C11orf30/LRRC32 locus, and the human leukocyte antigen region were identified using a multi-ethnic database (134). All of the identified loci are involved in epithelial barrier function or immunological regulation, highlighting the role of both mechanisms in the development of food allergy.

Twin studies have provided the strong evidences for the genetic determination of allergic diseases. A systematic review of twin and sibling studies suggests that the overlaps in loci between different allergic diseases may partly explain allergic co-morbidities and the concept of the "atopic march" (135). A Swedish cohort study including 25,306 twin aged 9 or 12 years showed that asthma and allergic diseases of childhood are greatly heritable. In this study, the heritability of any childhood asthma was 0.82 . For the other allergic diseases including wheezing, hay fever, atopic eczema, and food allergy, the range was $\sim 0.60-0.80$ (136). A twin study of eosinophilic esophagitis indicated the frequencies in both monozygotic and dizygotic twins were significantly higher than in siblings (137), suggesting 
that eosinophilic esophagitis also shows the heritability. These heritability estimates are variable in different studies, probably due to differences in study designs and target populations.

Racial disparities are also identified in allergic diseases. It has been shown that African Americans are sensitized to food and aeroallergens more frequently than whites (138). The analysis of genetic markers for the ancestry suggests that the racial disparities and ancestry are associated with elevated levels of food allergen-specific IgE (139). The effects of maternal asthma on racial/ethnic disparities in obstetrical and neonatal complications were tested (91). Analysis of data acquired from white $(N=$ $110,603)$, black $(N=50,284)$, and Hispanic $(N=38,831)$ singleton for joint effects of maternal race/ethnicity and asthma on the odds of obstetrical/neonatal complications indicated that maternal asthma status did not confer additional risks for asthma or complications (preeclampsia, neonatal intensive care unit admissions, maternal hemorrhage, small for gestational age, and apnea) to black women and their infants, while maternal asthma status increased risk for both asthma and many complications to white and Hispanic (91). A meta-analysis study demonstrated that maternal asthma is a greater risk for offspring asthma than paternal asthma (OR, 3.04 vs. $2.44, p=0.037$ ) (94). Maternal, but not paternal, total IgE levels correlated with elevated infant IgE levels and infant eczema (95). The effect of parental allergy on food allergy in children is yet to be discovered.

While these studies have been useful and will continue to identify novel genes for food allergy and other allergies, future approaches to investigate the mechanisms by which such genetic factors play a role in maternal influences over food allergy in offspring will improve our understanding of the disease mechanisms and produce potential opportunities for prevention and treatment of the disease.

\section{Food allergen consumption}

In contrast to potential preventive effects of allergen exposure that we discussed earlier in this article, an increased risk by maternal consumption of allergenic foods has been previously proposed. A study enrolled 503 infants 3 to 15 months of age with likely milk or egg allergy without previous diagnosis of peanut allergy and investigated the association of maternal peanut intake with peanut sensitization in offspring. They identified a dose-dependent association of maternal peanut ingestion during the third trimester of pregnancy with peanut sensitization in offspring (12). There was no significant effect of maternal peanut consumption during the first or second trimester of pregnancy or during breastfeeding on offspring peanut sensitization in this study. Among infants never breastfed, frequent ingestion of peanut during pregnancy was strongly associated with peanut sensitization in offspring. These results suggest that maternal consumption of peanut during pregnancy is a potential risk factor of offspring food sensitization, although oral food challenges were not performed due to the age of the group. Earlier study that investigated 13,971 children of non-atopic and atopic mothers reported no association of maternal peanut consumption during pregnancy with challenge-proven peanut allergy in preschool children (13). Effects of maternal and infant food-allergen avoidance on development of early onset atopy were investigated in a prenatally randomized, controlled trial of infants of atopic parents (28). Children of prophylactic-treated group $(N=103)$ (maternal avoidance of egg, cow's milk, and peanut during the third trimester of pregnancy and breastfeeding period, infant use of casein hydrolysate for supplementation or weaning, and avoidance of solid food for 6 months, avoidance of cow's milk, corn, citrus, and wheat for 12 months, and avoidance of egg, peanut, and fish for 24 months) showed a lower prevalence of atopy at 12 months compared to those in control group $(N=185)$ with unrestricted diets, occurring from reduced food-associated atopic dermatitis, urticaria, and/or gastrointestinal disease by 12 months $(p=0.007)$ and any positive food skin test by 24 months $(p=0.019)$ in the prophylactic-treated group. However, the suppression of prevalence of food allergy and milk sensitization was significant only before 2 years of age and none of the prevalence in food allergy, atopic dermatitis, allergic rhinitis, asthma, any atopic disease, and serum IgE levels were differed at 7 years of age (29), indicating that maternal and offspring avoidance of allergenic foods is not effective in prevention of allergic diseases in offspring.

\section{Allergen-specific Igs and cytokine}

As to Ig transmission, the mechanisms responsible for the acquisition of maternal antibodies other than IgG are not fully understood. Cord blood IgE has been proposed as a predictive marker for allergic diseases (140). However, it is suggested that cord blood allergen-specific IgE does not reflect intrauterine sensitization but rather is the result of maternal IgE transfer to the fetus, which is mediated by FcRn that accelerates the transepithelial transport of IgE in the form of IgE-IgG-IC (141, 142). The significance of this IC in allergy development in offspring has not been investigated. A birth cohort study has shown the association of prenatal cytokine production (cordblood concentrations of IL-4, IFN- $\gamma$, and tumor necrosis factor) with the development of atopy and asthma at 6 years of age. The study suggests that neonatal cytokine production patterns are significant predictors of a following risk for allergy and asthma (90). Another study indicated that maternal allergen sensitization is associated with reduced IFN- $\gamma$ production from stimulated maternal peripheral blood mononuclear cells and increased production of IL-13 in cord blood mononuclear cells from offspring (92).

\section{Microbiota}

Increasing evidences highlight the role of microbiota in development of allergies [reviewed in (143)]. Children born by caesarian section are suggested to be more susceptible to develop allergies, as appropriate exposure to microbiome of newborns through natural birth may be required for the maturation of their immune system in early life. Consistently, use of antibiotics by both mothers and children were associated with an increased risk of cow's milk allergy (88). In 2018, it is reported that maternal asthma status did not alter the microbial populations in the children. They showed that maternal asthma was, however, a key modifier between the microbiome and asthma risk, which pointed to susceptibility to host-microbial interactions particularly for these children (96). The study suggests that such 
susceptibility could occur from an inborn immune deviation determined by maternal asthma status (144).

\section{Dietary supplements}

Early-life exposures such as infection, environmental pollutants and nutrients provided via the mother may act upon the developing fetal immune system and lead to allergic diseases. Studies investigating the association of maternal nutrients such as vitamin D, PUFAs, and folate (or the synthetic form, folic acid) have been equivocal (145). Eicosanoids, signaling molecules made from PUFAs play a role in inducing inflammations. High levels of eicosanoids are associated with an increase in the prevalence and severity of allergic diseases (63). The association of high levels of maternal dietary intake of linoleic acid, a common n-6 fatty acid, both during pregnancy and after birth with an increased risk of allergic diseases in children has been demonstrated. A Finnish study showed that higher consumption of n-6 than n-3 during pregnancy was associated with higher risk of rhinoconjunctivitis in offspring at 5 years of age (89). A study on German schoolchildren in Leipzig in 1995-1996 ( $N=$ 2,334 ) showed that schoolchildren who consumed linoleic acidrich margarine exhibited a higher risk of hay fever as compared to schoolchildren who did not consume margarine (146). Similarly, a longitudinal study on Australian schoolchildren in 1980 showed higher levels of margarine consumption and lower levels of butter consumption among children with atopic disease as compared to non-atopic children (147). Since n-6 and n-3 compete for metabolism by the same enzyme, too high intake of $n-6$ would reduce the amount of enzyme available for $n-3$, decrease the $n-6 / n-3$ ratio, and result in the production of more proinflammatory modulators that may lead to inflammation including asthma (148). Maternal serum concentration of $\mathrm{Fe}$ states (ferritin concentration) during first-trimester of pregnancy was inversely correlated with risk of childhood wheeze and impaired lung function (81). Beneficial effects of maternal consumption of specific nutrients on preventing offspring are still largely unknown.

\section{Maternal health and environment}

Maternal health condition including control of maternal allergies and maternal exposure to certain chemicals are important factor to influence neonatal health condition. Maternal severe asthma without using inhalant corticosteroid treatment related to reduced birth weights of female children (149). However, prenatal exposure of preterm infants to dexamethasone, a type of corticosteroid medication, increased their susceptibility to allergic diseases, especially asthma and allergic rhinitis (82). In a Danish cohort study that employed 675,379 singletons, children from mothers with mild uncontrolled asthma, moderate-tosevere controlled asthma, and moderate-to-severe uncontrolled asthma showed higher prevalence of early-onset persistent asthma than those of mothers with mild controlled asthma (93), indicating that the severity and control of maternal asthma increase risk for offspring asthma. Although poorly controlled maternal asthma is associated with augmented risk of development of allergy, the use of corticosteroid during pregnancy is only recommended when there are no alternatives and benefit outweighs risk. Maternal exposure to $\mathrm{H} 2$ blockers or proton pump inhibitors also increase the risk of developing asthma, especially in children whose mothers purchased these medication more than 3 times within 2 months prior to conception and during pregnancy $(83,84)$. Preeclampsia, maternal pre-pregnancy overweight, and maternal obesity were associated with an increased risk of wheezing in offspring in a pooled analysis of 14 birth cohort studies (85). High levels of maternal exposure during pregnancy to phthalate reduced the number of Treg cells in cord blood as well as in children aged 2 years (86). Furthermore, high concentrations of phthalate metabolites in maternal urine were significantly associated with a higher risk for atopic dermatitis in children until 3 years of age (OR, 2.21; $p=0.026)$. The study suggests that the reduction in Treg cells in offspring by maternal exposure to phthalate may facilitate the development of atopic dermatitis in early childhood.

Maternal adverse life events such as separation or divorce, marital problems, problems with the children, pregnancy problems, involuntary job loss experience, involuntary job loss of partner, money problems, a residential move, death of a close relative, and death of a close friend during pregnancy are suggested to link an increased risk for atopic disorders in offspring (87).

In addition to genetic predispositions linked to allergies, these studies clearly suggest a critical involvement of maternal health and environmental factors in the development and manifestation of allergy in offspring. Optimal management of maternal health might be essential in determining the allergic predisposition and clinical symptoms in offspring.

\section{Breastfeeding}

\section{Allergen, allergen-specific Igs, and cytokine}

Maternal and environmental factors modify the milk composition and may facilitate development of allergic diseases in neonate. Dietary allergens such as peanut, egg, and cow's milk proteins have been detected in human milk $(72,150-152)$ and may induce symptoms in already sensitized infants (152). However, their role in early sensitization vs. tolerance induction in offspring is still unclear. Airborne allergens from house dust mite are contained in human breast milk that may facilitate sensitization to food allergens in mice (153). Infants with cow's milk allergy have specific IgE that cross-reacts with endogenous human protein in breast milk (154), potentially suggesting that cow's milk allergy may trigger allergic march because cow's milk proteins could be the first foreign proteins recognized by infant. Breastfeeding may increase a risk for atopic eczema and food allergy in breast-fed infant (155). As we discussed earlier, food avoidance by allergic mothers was associated with offspring allergy (75). Lower levels of milk-specific IgG4 and IgA in allergic mothers who have eliminated milk from their diet during breastfeeding were associated with the development of cow's milk allergy, implying the potential protective roles of maternal food allergen consumption against offspring allergies via food-specific IgG4 and IgA in breast milk. Concentrations of chemoattractant factors were higher in breast milk of allergic mothers than in those of non-allergic mothers. The breast milk of allergic mothers contained higher levels of IL-4, regulated on 
activation, normal T cell expressed and secreted (RANTES) and IL-8 as compared to those of non-allergic mothers (97). Another study reported that the levels of IL-1 $\beta$ ( $p=0.001)$, IL-10 ( $p=$ $0.04)$, and $\beta$-lactoglobulin-specific $\operatorname{IgA}(p=0.005)$ were lower in breast milk from mothers of infants with cow's milk allergy than in breast milk from mothers of infants without cow's milk allergy (98). The component of breast milk of allergic mothers may be different from that of non-allergic mothers, although the effects of these differences on offspring allergies are poorly understood.

\section{Perspective}

Evidences indicate that genetics are one of the most critical factors that determine the susceptibility of allergic sensitization and severity of allergic symptoms in the offspring. The impacts of genetics are likely amplified by maternal nutrition and environmental factors including drug usage and exposure to harmful chemicals during pregnancy. Breastfeeding by allergic mothers may be another modifier of allergic reactions in offspring. Allergen, Ig, and IC transferred in utero and via breast milk likely play important roles in promoting the susceptibility of offspring by regulating the balance of Th2 vs. Treg cell responses. It is still unclear which factor is crucial to determine susceptibility to allergic sensitization and clinical manifestation of allergic inflammation in offspring (Table 2). Further prospective birth cohort studies and meta-analysis are needed to elucidate crucial risk factors for allergic sensitization in offspring transferred from allergic mothers.

\section{Mouse Studies}

In this section, we focus on literatures demonstrated the increased susceptibility of offspring from allergic dams to allergic inflammation and discuss the role of maternal transmission of allergies to offspring.

\section{Preconceptional and in utero Factors Cytokine, T cell, and genetic factors}

Mouse models of experimental allergies have been utilized to dissect how maternal factors affect the susceptibility of offspring to allergic inflammation. The susceptibility of offspring from asthmatic dams to development of allergic airway inflammation has been intensely studied. Hamada et al. preconceptionally immunized BALB/c WT dams with OVA/alum and exposed to OVA aerosol during pregnancy. Offspring of OVA-dams, but not of unsensitized dams, exhibited allergic airway inflammation in response to suboptimal sensitization with OVA/alum and OVA aerosol, suggesting maternal transfer of asthma risk to offspring (107). This model of maternal transmission of asthma risk to offspring was not allergen-specific (107), as offspring of asthmatic dams sensitized and challenged with OVA also showed higher responsiveness to casein-induced allergic airway inflammation. Blocking of IL-4 signaling in asthmatic dams by administration of anti-IL- 4 antibodies before mating abolished the increased susceptibility of offspring from asthmatic dams to suboptimal sensitization protocol, suggesting that the maternal transfer of asthma risk to offspring is IL-4 dependent (107). Th2 responses in asthmatic dams skewed fatal and neonatal immunity toward Th2 and were associated with the increased asthma susceptibility in offspring that persisted through the young adulthood ( $\sim 3$ or 6 weeks) in offspring $(156,157)$. Adoptive transfer of DO11.10-derived $\mathrm{T}$ cells to naive dams prior to mating resulted in higher responsiveness of offspring to suboptimal challenge of OVA (108). Donor T cells were identified in spleen and placenta of the recipient female dams but were not detectable in fetal tissues, suggesting that the factors produced by maternal allergen-specific $\mathrm{T}$ cells mediated the response. Naïve offspring of asthmatic dams showed significantly high levels of spleen cellularity due to an increase in $\mathrm{CD}^{+}{ }^{+} \mathrm{CD} 25^{+}$Foxp $^{-}$effector T cell population (109). Interestingly, depletion of CD25 $5^{\text {high }} \mathrm{T}$ cell population by antiCD25 antibody (clone PC61) in 4-day-old newborn mice before induction of airway inflammation by suboptimal sensitization protocol resulted in the increased susceptibility to allergic airway inflammation in normal offspring. In contrast, depletion of CD25 high $\mathrm{T}$ cell resulted in a substantial reduction in asthma symptoms in offspring of allergic dams. Anti-glucocorticoidinduced tumor necrosis factor receptor-family related receptor (GITR) antibody (clone DTA-1) treatment before induction of airway inflammation with suboptimal sensitization protocol significantly attenuated the susceptibilities to allergic airway inflammation in offspring of both naïve and asthmatic dams. Contrary, anti-GITR antibody treatment after induction of airway inflammation enhanced the development of asthmalike allergic inflammation in normal offspring, but induced only a slight deterioration of allergic airway inflammation in the offspring of asthmatic dams. The authors suggest that the increased asthma susceptibility in offspring of asthmatic dams can be prevented by modulating maternal Th2 responses as well as neonatal regulatory responses with anti-CD25 (presensitization in asthma-prone offspring) or -GITR antibodies (pre-sensitization in both normal and asthma-prone offspring). As OVA-dams were not exposed to OVA during lactation, these data may indicate that lack of allergen transfer through milk together with maternal sensitization is critical for maternal transmission of asthma risk to offspring (51, 118, 156, 158-160).

Skin barrier impairment also affects the susceptibility to food allergy in offspring born from allergen-sensitized dams. WT dams were i.p. sensitized with OVA/alum and exposed to OVA aerosols before mating with unsensitized flaky tail (ft) male mice that exhibit an impaired skin barrier due to homozygous mutations of filaggrin (Flg) and mattrin (Tmem79 $\left.{ }^{m a}\right)$ genes $\left(F l g^{f t / f t} /\right.$ Tmem $\left.79^{m a / m a}\right)$. Resulting Flgft/+/Tmem $79^{m a /+}$ offspring showed an increase in food allergen sensitization, serum mMCP1, and anaphylaxis to food allergen sensitization through tape stripped skin with peanut extract and Alternaria alternate extract followed by food allergen challenge compared to those born from unsensitized WT dams (110). These food allergic responses were associated with higher levels of transcripts for CCL11, TSLP and IL-33 in the skin, and TSLP in the jejunum. This study suggests the possibility that responses to food allergens of neonatal mice are dependent on genetic defects in cutaneous barrier function and on exposure to environmental allergens. 


\section{Breastfeeding}

Both maternal allergic sensitization and allergen consumption seem to alter the immunological components of breast milk that affect offspring allergy. Using the mouse model of maternal asthma transfer as discussed above, Leme et al. demonstrated the role of breast milk from allergen-sensitized dams in the development of allergy in offspring (161). Both offspring from asthmatic dams nursed by unsensitized dams and offspring from unsensitized dams nursed by asthmatic dams showed enhanced airway hyperresponsiveness and allergic airway inflammation after allergen sensitization compared to offspring from and nursed by unsensitized dams. The authors suggest an equal transmission of asthma to the offspring either in utero or through breast milk.

With regards to food allergy, Song et al. demonstrate that maternal peanut allergy increases susceptibility to offspring allergy in link with Th2-biased epigenetic alterations in a mouse model of peanut allergy (118). $\mathrm{C} 3 \mathrm{H} / \mathrm{HeJ}$ dams were sensitized with oral peanut/CT and challenged before mating. Offspring of dams sensitized and challenged with peanut exhibited increased food allergic responses following suboptimal dose of oral peanut/CT sensitization and peanut challenge, associated with hypomethylation at $\mathrm{CPG}$ sites of Il4 gene promoter. Interestingly, unlike their previous study demonstrating that maternal exposure to peanut during pregnancy and lactation reduces peanut allergy risk in offspring (17), dams did not receive sensitization during pregnancy and breastfeeding in this study. These results suggest that maternal sensitization may increase food allergy susceptibility in offspring in the absence of maternal allergen exposure during pregnancy and breastfeeding. Together, these studies suggest that maternal immune responses during lactation are critical for the reduction of food allergy susceptibility in offspring, consistent with the increasing numbers of studies demonstrating that breastfeeding by allergensensitized dams results in the induction of tolerance rather than the maternal risk transfer (as discussed in section Breastfeeding in Mouse studies for maternal protective influences).

\section{Perspective}

In some mouse studies, offspring of asthmatic dams have been shown to be more susceptible to asthma than offspring of non-allergic dams. However, the efficacy of breastfeeding by asthmatic dams in ameliorating allergic symptoms have not been thoroughly investigated. It is currently unclear whether offspring of allergic dams who did not receive breast milk may exhibit higher susceptibilities to allergies and move severe allergies than breastfed offspring. Multitudes of factors likely contribute to the maternal life during pregnancy and breastfeeding period, including allergen exposure and allergic responses. Depending on doses, timing, and number of antigen challenges, multiple factors in breast milk could transfer mediators that either increase or decrease offspring responses to allergen (Table 3). In the recent dramatic shift in recommendations from avoidance of common food allergens to early ingestion to prevent the development of allergy in offspring support the concept that early allergen introduction, potentially through breastfeeding, may decrease the risk of offspring allergies. Investigations of exact timing and dose of allergen exposure as well as early critical factors are necessary for development of safe and effective strategies for high-risk infant.

\section{CONCLUSIONS}

Evidences from human and mouse studies suggest that maternal allergen exposure and resulting maternal immune responses that are transferred through placenta and breast milk likely influence offspring immune responses toward those allergens. Such interactions are regulated by genetic factors and environmental factors (maternal microbiota, nutrients, and health) to determine the induction of tolerance vs. allergy outcome in offspring through Th1, Th2, and Treg cell responses.

Current human data are not sufficient to draw firm conclusions regarding the role of breastfeeding in preventing or delaying the development of food allergies in offspring (69), however, there is now evidence that early introduction of peanuts may prevent peanut allergy (Table 1). Mouse studies suggesting maternal transfer of asthma risk to offspring lack maternal allergen exposure during pregnancy and breastfeeding. Other studies suggest maternal transmission of tolerance to offspring against asthma through breast milk allergen and IC. Although the investigations using experimental food allergy within this area are still developing, those studies consistently suggest that maternal sensitization and exposure with allergen induce tolerance in offspring, especially via breast milk. These results from experimental asthma and food allergy models may seem inconsistent at first glance, yet they are consistent in that maternal allergen sensitization plus allergen exposure during pregnancy and breastfeeding, which are likely tolerogenic periods, are critical in the induction of tolerance vs. allergies in offspring (Table 3). Those studies, including our own, are in line with several recent findings in humans as (1) maternal exposure to food allergens reduces allergy in offspring in humans, (2) recent decisions to cancel recommendations of allergen avoidance during pregnancy and breastfeeding, and (3) early food introduction potentially decreasing the risk of food allergy development. The last finding is particularly relevant to the results from mouse studies, as food allergen transfer via milk may be the first food exposure for the infant.

Development of a feasible and optimal instruction for maternal and offspring consumption of potentially allergenic food and nutrient during pregnancy and breastfeeding are urgently needed. Thorough analysis of human amniotic fluid and breast milk component based on challenge-proven food allergies in offspring in combination with genetic analysis may help with development of such instruction. Consideration of dose, frequencies, and period of food consumption during pregnancy and breastfeeding together with nutrient or immunological supplementation of breast milk may help with the novel strategies for prevention and treatment of food allergy in offspring.

The precise mechanisms by which maternal factors, such as allergen exposure during breastfeeding, exert a lasting effect on determining the susceptibility of offspring toward allergy need further investigations. Findings in mouse studies need to be 
carefully interpreted due to the differences between mice and humans. However, the powers of animal models are being able to investigate specific questions that are impossible or unethical to address in human subjects. To date, epidemiological studies have been performed at population levels and not at personal levels. Combined future research of translational and clinical science will help us with understandings of the role of maternal factors on offspring food allergy and will lead to effective preventive care of the disease.

\section{AUTHOR CONTRIBUTIONS}

TF, SL, YN, and MO wrote the paper. TF and MO arranged and revised the manuscript. SK and MO conceived and supervised the paper. TF, SL, and MO have agreed to be accountable for all aspects of the manuscript and in securing that questions related

\section{REFERENCES}

1. Pawankar R, Canonika GW, Holgate ST, Lockey RF. WAO White Book on Allergy 2011-2012: Executive Summary. Milwaukee, WI: World Allergy Organization (2011).

2. Sterner T, Uldahl A, Svensson A, Bjork J, Svedman C, Nielsen C, et al. The southern Sweden adolescent allergy-cohort: prevalence of allergic diseases and cross-sectional associations with individual and social factors. J Asthma. (2019) 56:227-35. doi: 10.1080/02770903.2018.1452033

3. Sicherer SH, Sampson HA. Food allergy: epidemiology, pathogenesis, diagnosis, and treatment. J Allergy Clin Immunol. (2014) 133:291-307. doi: 10.1016/j.jaci.2013.11.020

4. Mehaudy R, Parisi C, Petriz N, Eymann A, Jauregui MB, Orsi M. Prevalence of cow's milk protein allergy among children in a university community hospital. Arch Argent Pediatr. (2018) 116:219-23. doi: 10.5546/aap.2018.eng.219

5. Anvari S, Miller J, Yeh CY, Davis CM. IgE-mediated food allergy. Clin Rev Allergy Immunol. (2018). doi: 10.1007/s12016-018-8710-3. [Epub ahead of print].

6. Prescott S, Allen KJ. Food allergy: riding the second wave of the allergy epidemic. Pediatr Allergy Immunol. (2011) 22:155-60. doi: 10.1111/j.1399-3038.2011.01145.x

7. Iweala OI, Choudhary SK, Commins SP. Food allergy. Curr Gastroenterol Rep. (2018) 20:17. doi: 10.1007/s11894-018-0624-y

8. McWilliam V, Koplin J, Lodge C, Tang M, Dharmage S, Allen K. The prevalence of tree nut allergy: a systematic review. Curr Allergy Asthma Rep. (2015) 15:54. doi: 10.1007/s11882-015-0555-8

9. Rudders SA, Banerji A, Vassallo MF, Clark S, Camargo CA Jr. Trends in pediatric emergency department visits for food-induced anaphylaxis. $J$ Allergy Clin Immunol. (2010) 126:385-8. doi: 10.1016/j.jaci.2010.05.018

10. Keet CA, Allen KJ. Advances in food allergy in 2017. J Allergy Clin Immunol. (2018) 142:1719-9. doi: 10.1016/j.jaci.2018.10.020

11. Sicherer SH, Burks AW, Sampson HA. Clinical features of acute allergic reactions to peanut and tree nuts in children. Pediatrics. (1998) 102:e6. doi: $10.1542 /$ peds.102.1.e6

12. Sicherer SH, Wood RA, Stablein D, Lindblad R, Burks AW, Liu AH, et al. Maternal consumption of peanut during pregnancy is associated with peanut sensitization in atopic infants. J Allergy Clin Immunol. (2010) 126:1191-7. doi: 10.1016/j.jaci.2010.08.036

13. Lack G, Fox D, Northstone K, Golding J. Factors associated with the development of peanut allergy in childhood. N Engl J Med. (2003) 348:97785. doi: 10.1056/NEJMoa013536

14. Bunyavanich S, Rifas-Shiman SL, Platts-Mills TA, Workman L, Sordillo JE, Camargo CA Jr, et al. Peanut, milk, and wheat intake during pregnancy is associated with reduced allergy and asthma in children. J Allergy Clin Immunol. (2014) 133:1373-82. doi: 10.1016/j.jaci.2013.11.040 to the accuracy of any part of the manuscript. MO has given a final approval of the version of the manuscript to be published.

\section{FUNDING}

This study was supported by the National Institute of Allergy and Infectious Diseases of the National Institutes of Health under Award Number R01AI142872, and the Food Allergy Research \& Education, Inc., the HOPE APFED/ARTrust ${ }^{\mathrm{TM}}$ Pilot Grant, the William F. Milton Fund, the Harvard Catalyst Clinical and Translational Research Center (NCATS grant \#8UL 1TR000170), and the Boston Children's Hospital Pediatric Associates Award (MO). TF and SK are supported by Program for Fostering Globally Talented Researchers, Japan Society for the Promotion of Science (JSPS), Japan.

15. Frazier AL, Camargo CA Jr, Malspeis S, Willett WC, Young MC. Prospective study of peripregnancy consumption of peanuts or tree nuts by mothers and the risk of peanut or tree nut allergy in their offspring. JAMA Pediatr. (2014) 168:156-62. doi: 10.1001/jamapediatrics.2013.4139

16. Fusaro AE, Brito CA, Victor JR, Rigato PO, Goldoni AL, Duarte $\mathrm{AJ}$, et al. Maternal-fetal interaction: preconception immunization in mice prevents neonatal sensitization induced by allergen exposure during pregnancy and breastfeeding. Immunology. (2007) 122:107-15. doi: 10.1111/j.1365-2567.2007.02618.x

17. Lopez-Exposito I, Song Y, Jarvinen KM, Srivastava K, Li XM. Maternal peanut exposure during pregnancy and lactation reduces peanut allergy risk in offspring. J Allergy Clin Immunol. (2009) 124:1039-46. doi: 10.1016/j.jaci.2009.08.024

18. Mosconi E, Rekima A, Seitz-Polski B, Kanda A, Fleury S, Tissandie E, et al. Breast milk immune complexes are potent inducers of oral tolerance in neonates and prevent asthma development. Mucosal Immunol. (2010) 3:461-74. doi: 10.1038/mi.2010.23

19. Verhasselt V. Oral tolerance in neonates: from basics to potential prevention of allergic disease. Mucosal Immunol. (2010) 3:326-33. doi: $10.1038 / \mathrm{mi} .2010 .25$

20. Pastor-Vargas C, Maroto AS, Diaz-Perales A, Villalba M, Esteban V, RuizRamos M, et al. Detection of major food allergens in amniotic fluid: initial allergenic encounter during pregnancy. Pediatr Allergy Immunol. (2016) 27:716-20. doi: 10.1111/pai.12608

21. Hourihane JO, Aiken R, Briggs R, Gudgeon LA, Grimshaw KE, DunnGalvin A, et al. The impact of government advice to pregnant mothers regarding peanut avoidance on the prevalence of peanut allergy in United Kingdom children at school entry. J Allergy Clin Immunol. (2007) 119:1197-202. doi: 10.1016/j.jaci.2006.12.670

22. Du Toit G, Tsakok T, Lack S, Lack G. Prevention of food allergy. J Allergy Clin Immunol. (2016) 137:998-1010. doi: 10.1016/j.jaci.2016.02.005

23. Kramer MS, Kakuma R. Maternal dietary antigen avoidance during pregnancy or lactation, or both, for preventing or treating atopic disease in the child. Cochrane Database Syst Rev. (2012) CD000133. doi: 10.1002/14651858.CD000133.pub3

24. Cook-Mills JM. Maternal influences over offspring allergic responses. Curr Allergy Asthma Rep. (2015) 15:501. doi: 10.1007/s11882-014-0501-1

25. Du Toit G, Foong RM, Lack G. Prevention of food allergy - early dietary interventions. Allergol Int. (2016) 65:370-7. doi: 10.1016/j.alit.2016.08.001

26. Pitt TJ, Becker AB, Chan-Yeung M, Chan ES, Watson WTA, Chooniedass $\mathrm{R}$, et al. Reduced risk of peanut sensitization following exposure through breast-feeding and early peanut introduction. J Allergy Clin Immunol. (2018) 141:620-5. doi: 10.1016/j.jaci.2017.06.024

27. Tuokkola J, Luukkainen P, Tapanainen H, Kaila M, Vaarala O, Kenward MG, et al. Maternal diet during pregnancy and lactation and cow's milk allergy in offspring. Eur J Clin Nutr. (2016) 70:554-9. doi: 10.1038/ejcn.2015.223 
28. Zeiger RS, Heller S, Mellon MH, Forsythe AB, O'Connor RD, Hamburger $\mathrm{RN}$, et al. Effect of combined maternal and infant food-allergen avoidance on development of atopy in early infancy: a randomized study. J Allergy Clin Immunol. (1989) 84:72-89. doi: 10.1016/0091-6749(89) 90181-4

29. Zeiger RS, Heller S. The development and prediction of atopy in high-risk children: follow-up at age seven years in a prospective randomized study of combined maternal and infant food allergen avoidance. J Allergy Clin Immunol. (1995) 95:1179-90. doi: 10.1016/S0091-6749(95)70074-9

30. Chiu CY, Liao SL, Su KW, Tsai MH, Hua MC, Lai SH, et al. Exclusive or partial breastfeeding for 6 months is associated with reduced milk sensitization and risk of eczema in early childhood: the patch birth cohort study. Medicine. (2016) 95:e3391. doi: 10.1097/MD.0000000000003391

31. van Ginkel CD, van der Meulen GN, Bak E, Flokstra-de Blok BMJ, Kollen BJ, Koppelman GH, et al. Retrospective observational cohort study regarding the effect of breastfeeding on challenge-proven food allergy. Eur J Clin Nutr. (2018) 72:557-63. doi: 10.1038/s41430-018-0117-y

32. Klopp A, Vehling L, Becker AB, Subbarao P, Mandhane PJ, Turvey SE, et al. Modes of infant feeding and the risk of childhood asthma: a prospective birth cohort study. J Pediatr. (2017) 190:192-9. doi: 10.1016/j.jpeds.2017.07.012

33. Azad MB, Vehling L, Lu Z, Dai D, Subbarao P, Becker AB, et al. Breastfeeding, maternal asthma and wheezing in the first year of life: a longitudinal birth cohort study. Eur Respir J. (2017) 49:1602019. doi: 10.1183/13993003.02019-2016

34. Du Toit G, Roberts G, Sayre PH, Bahnson HT, Radulovic S, Santos AF, et al. Randomized trial of peanut consumption in infants at risk for peanut allergy. N Engl J Med. (2015) 372:803-13. doi: 10.1056/NEJMoa1414850

35. Du Toit G, Roberts G, Sayre PH, Plaut M, Bahnson HT, Mitchell H, et al. Identifying infants at high risk of peanut allergy: the Learning Early About Peanut Allergy (LEAP) screening study. J Allergy Clin Immunol. (2013) 131:135-43. doi: 10.1016/j.jaci.2012.09.015

36. Perkin MR, Logan K, Marrs T, Radulovic S, Craven J, Flohr C, et al. Enquiring About Tolerance (EAT) study: feasibility of an early allergenic food introduction regimen. J Allergy Clin Immunol. (2016) 137:1477-86. doi: 10.1016/j.jaci.2015.12.1322

37. Ehrlich P. Ueber immunität durch vererbung und säugung (in German). Z Hyg. Infektionskrankheiten Med. Mikrobiol. Immunol. Virol. (1892) 12:183-203. doi: 10.1007/BF022 84236

38. Antohe F, Radulescu L, Gafencu A, Ghetie V, Simionescu M. Expression of functionally active FcRn and the differentiated bidirectional transport of IgG in human placental endothelial cells. Hum Immunol. (2001) 62:93-105. doi: 10.1016/S0198-8859(00)00244-5

39. Oykhman P, Kim HL, Ellis AK. Allergen immunotherapy in pregnancy. Allergy Asthma Clin Immunol. (2015) 11:31. doi: 10.1186/s13223-015-0096-7

40. Flicker S, Marth K, Kofler H, Valenta R. Placental transfer of allergen-specific IgG but not IgE from a specific immunotherapy-treated mother. J Allergy Clin Immunol. (2009) 124:1358-60. doi: 10.1016/j.jaci.2009.09.024

41. Glovsky MM, Ghekiere L, Rejzek E. Effect of maternal immunotherapy on immediate skin test reactivity, specific rye I IgG and IgE antibody, and total IgE of the children. Ann Allergy. (1991) 67:21-4.

42. Jenmalm MC, Bjorksten B. Cord blood levels of immunoglobulin G subclass antibodies to food and inhalant allergens in relation to maternal atopy and the development of atopic disease during the first 8 years of life. Clin Exp Allergy. (2000) 30:34-40. doi: 10.1046/j.1365-2222.2000.00771.x

43. Bager P, Wohlfahrt J, Westergaard T. Caesarean delivery and risk of atopy and allergic disease: meta-analyses. Clin Exp Allergy. (2008) 38:634-42. doi: 10.1111/j.1365-2222.2008.02939.x

44. Cuppari C, Manti S, Salpietro A, Alterio T, Arrigo T, Leonardi S, et al. Mode of delivery and risk for development of atopic diseases in children. Allergy Asthma Proc. (2015) 36:344-51. doi: 10.2500/aap.2015.36.3870

45. Thavagnanam S, Fleming J, Bromley A, Shields MD, Cardwell CR. A metaanalysis of the association between caesarean section and childhood asthma. Clin Exp Allergy. (2008) 38:629-33. doi: 10.1111/j.1365-2222.2007.02780.x

46. Radano MC, Yuan Q, Katz A, Fleming JT, Kubala S, Shreffler W, et al. Cesarean section and antibiotic use found to be associated with eosinophilic esophagitis. J Allergy Clin Immunol Pract. (2014) 2:475-7. doi: 10.1016/j.jaip.2014.02.018
47. Romagnani S. Immunologic influences on allergy and the Th1/Th2 balance J Allergy Clin Immunol. (2004) 113:395-400. doi: 10.1016/j.jaci.2003.11.025

48. Liao SL, Tsai MH, Yao TC, Hua MC, Yeh KW, Chiu CY, et al. Caesarean section is associated with reduced perinatal cytokine response, increased risk of bacterial colonization in the airway, and infantile wheezing. Sci Rep. (2017) 7:9053. doi: 10.1038/s41598-017-07894-2

49. Balossini V, Monzani A, Rapa A, Vivenza D, Caristo E, Oderda G. Interleukin-10 and transforming growth factor-betal in cord blood: Relationship with paternal allergy and cesarean section. Acta Paediatr. (2009) 98:812-6. doi: 10.1111/j.1651-2227.2008.01194.x

50. Taylor A, Verhagen J, Blaser K, Akdis M, Akdis CA. Mechanisms of immune suppression by interleukin-10 and transforming growth factorbeta: the role of $\mathrm{T}$ regulatory cells. Immunology. (2006) 117:433-42. doi: 10.1111/j.1365-2567.2006.02321.x

51. Herz U, Joachim R, Ahrens B, Scheffold A, Radbruch A, Renz H. Prenatal sensitization in a mouse model. Am J Respir Crit Care Med. (2000) 162:S62-5. doi: 10.1164/ajrccm.162.supplement_2.ras-1

52. Khan TK, Palmer DJ, Prescott SL. In-utero exposures and the evolving epidemiology of pediatric allergy. Curr Opin Allergy Clin Immunol. (2015) 15:402-8. doi: 10.1097/ACI.0000000000000209

53. Grieger JA, Clifton VL, Tuck AR, Wooldridge AL, Robertson SA, Gatford KL. In utero programming of allergic susceptibility. Int Arch Allergy Immunol. (2016) 169:80-92. doi: 10.1159/000443961

54. Feng $\mathrm{H}$, Xun P, Pike K, Wills AK, Chawes BL, Bisgaard $\mathrm{H}$, et al. In utero exposure to 25-hydroxyvitamin D and risk of childhood asthma, wheeze, and respiratory tract infections: a meta-analysis of birth cohort studies. J Allergy Clin Immunol. (2016) 139:1508-17. doi: 10.1016/j.jaci.2016.06.065

55. Litonjua AA, Lange NE, Carey VJ, Brown S, Laranjo N, Harshfield $\mathrm{BJ}$, et al. The vitamin $\mathrm{D}$ antenatal asthma reduction trial (VDAART): rationale, design, and methods of a randomized, controlled trial of vitamin D supplementation in pregnancy for the primary prevention of asthma and allergies in children. Contemp Clin Trials. (2014) 38:37-50. doi: 10.1016/j.cct.2014.02.006

56. Litonjua AA, Carey VJ, Laranjo N, Harshfield BJ, McElrath TF, O'Connor GT, et al. Effect of prenatal supplementation with vitamin D on asthma or recurrent wheezing in offspring by age 3 years: the VDAART randomized clinical trial. JAMA. (2016) 315:362-70. doi: 10.1001/jama.2015.18589

57. Wolsk HM, Harshfield BJ, Laranjo N, Carey VJ, O'Connor G, Sandel M, et al. Vitamin D supplementation in pregnancy, prenatal 25(OH)D levels, race, and subsequent asthma or recurrent wheeze in offspring: secondary analyses from the vitamin D antenatal asthma reduction trial. J Allergy Clin Immunol. (2017) 140:1423-9. doi: 10.1016/j.jaci.2017.01.013

58. Chawes BL, Bonnelykke K, Stokholm J, Vissing NH, Bjarnadottir E, Schoos AM, et al. Effect of vitamin D3 supplementation during pregnancy on risk of persistent wheeze in the offspring: a randomized clinical trial. JAMA. (2016) 315:353-61. doi: 10.1001/jama.2015.18318

59. Wolsk HM, Chawes BL, Litonjua AA, Hollis BW, Waage J, Stokholm $\mathrm{J}$, et al. Prenatal vitamin D supplementation reduces risk of asthma/recurrent wheeze in early childhood: a combined analysis of two randomized controlled trials. PLoS ONE. (2017) 12:e0186657. doi: 10.1371/journal.pone.0186657

60. Hansen S, Maslova E, Strom M, Linneberg A, Halldorsson TI, Granstrom C, et al. The long-term programming effect of maternal 25-hydroxyvitamin $\mathrm{D}$ in pregnancy on allergic airway disease and lung function in offspring after 20 to 25 years of follow-up. J Allergy Clin Immunol. (2015) 136:169-76. doi: 10.1016/j.jaci.2014.12.1924

61. Osborne NJ, Ukoumunne OC, Wake M, Allen KJ. Prevalence of eczema and food allergy is associated with latitude in Australia. J Allergy Clin Immunol. (2012) 129:865-7. doi: 10.1016/j.jaci.2012.01.037

62. Koplin JJ, Suaini NH, Vuillermin P, Ellis JA, Panjari M, Ponsonby AL, et al. Polymorphisms affecting vitamin D-binding protein modify the relationship between serum vitamin $\mathrm{D}(25[\mathrm{OH}] \mathrm{D} 3)$ and food allergy. J Allergy Clin Immunol. (2016) 137:500-6. doi: 10.1016/j.jaci.2015. 05.051

63. Miles EA, Calder PC. Can early omega-3 fatty acid exposure reduce risk of childhood allergic disease? Nutrients. (2017) 9:784. doi: 10.3390/nu9070784

64. Yaqoob P, Calder PC. Fatty acids and immune function: new insights into mechanisms. Br J Nutr. (2007) 98:S41-5. doi: 10.1017/S0007114507832995 
65. Bisgaard H, Stokholm J, Chawes BL, Vissing NH, Bjarnadottir E, Schoos AM, et al. Fish oil-derived fatty acids in pregnancy and wheeze and asthma in offspring. N Engl J Med. (2016) 375:2530-9. doi: 10.1056/NEJMoa1503734

66. Dunstan JA, Mori TA, Barden A, Beilin LJ, Taylor AL, Holt PG, et al. Fish oil supplementation in pregnancy modifies neonatal allergen-specific immune responses and clinical outcomes in infants at high risk of atopy: a randomized, controlled trial. J Allergy Clin Immunol. (2009) 112:1178-84. doi: 10.1016/j.jaci.2003.09.009

67. Miyake Y, Sasaki S, Tanaka K, Ohfuji S, Hirota Y. Maternal fat consumption during pregnancy and risk of wheeze and eczema in Japanese infants aged 16-24 months: the Osaka maternal and child health study. Thorax. (2009) 64:815-21. doi: 10.1136/thx.2009.115931

68. Palmer DJ, Sullivan T, Gold MS, Prescott SL, Heddle R, Gibson RA, et al. Effect of n-3 long chain polyunsaturated fatty acid supplementation in pregnancy on infants' allergies in first year of life: randomized controlled trial. BMJ. (2012) 344:e184. doi: 10.1136/bmj.e184

69. Greer FR, Sicherer SH, Burks AW. The effects of early nutritional interventions on the development of atopic disease in infants and children: the role of maternal dietary restriction, breastfeeding, hydrolyzed formulas, and timing of introduction of allergenic complementary foods. Pediatrics. (2019) 143:e20190281. doi: 10.1542/peds.2019-0281

70. Du Toit G, Sayre PH, Roberts G, Lawson K, Sever ML, Bahnson HT, et al. Allergen specificity of early peanut consumption and effect on development of allergic disease in the learning early about peanut allergy study cohort. $J$ Allergy Clin Immunol. (2018) 141:1343-53. doi: 10.1016/j.jaci.2017.09.034

71. Schocker F, Scharf A, Kull S, Jappe U. Detection of the peanut allergens Ara h 2 and Ara h 6 in human breast milk: development of 2 sensitive and specific sandwich ELISA assays. Int Arch Allergy Immunol. (2017) 174:17-25. doi: $10.1159 / 000479388$

72. Bernard H, Ah-Leung S, Drumare MF, Feraudet-Tarisse C, Verhasselt V, Wal JM, et al. Peanut allergens are rapidly transferred in human breast milk and can prevent sensitization in mice. Allergy. (2014) 69:888-97. doi: 10.1111/all.12411

73. Hochwallner H, Alm J, Lupinek C, Johansson C, Mie A, Scheynius A, et al. Transmission of allergen-specific IgG and IgE from maternal blood into breast milk visualized with microarray technology. J Allergy Clin Immunol. (2014) 134:1213-5. doi: 10.1016/j.jaci.2014.08.041

74. Ohsaki A, Venturelli N, Buccigrosso TM, Osganian SK, Lee J, Blumberg RS, et al. Maternal IgG immune complexes induce food allergen-specific tolerance in offspring. J Exp Med. (2018) 215:91-113. doi: $10.1084 /$ jem. 20171163

75. Jarvinen KM, Westfall JE, Seppo MS, James AK, Tsuang AJ, Feustel PJ, et al. Role of maternal elimination diets and human milk IgA in the development of cow's milk allergy in the infants. Clin Exp Allergy. (2014) 44:69-78. doi: $10.1111 /$ cea. 12228

76. Hua MC, Chen CC, Yao TC, Tsai MH, Liao SL, Lai SH, et al. Role of maternal allergy on immune markers in colostrum and secretory immunoglobulin A in stools of breastfed infants. J Hum Lact. (2016) 32:1607. doi: 10.1177/0890334415598783

77. Oddy WH, Rosales F. A systematic review of the importance of milk TGFbeta on immunological outcomes in the infant and young child. Pediatr Allergy Immunol. (2010) 21:47-59. doi: 10.1111/j.1399-3038.2009.00913.x

78. Munblit D, Treneva M, Peroni DG, Colicino S, Chow LY, Dissanayeke $\mathrm{S}$, et al. Immune components in human milk are associated with early infant immunological health outcomes: a prospective three-country analysis. Nutrients. (2017) 9:532. doi: 10.3390/nu9060532

79. Jepsen AA, Chawes BL, Carson CG, Schoos AM, Thysen AH, Waage J, et al. High breast milk IL-1beta level is associated with reduced risk of childhood eczema. Clin Exp Allergy. (2016) 46:1344-54. doi: 10.1111/cea. 12770

80. Munblit D, Verhasselt V. Allergy prevention by breastfeeding: possible mechanisms and evidence from human cohorts. Curr Opin Allergy Clin Immunol. (2016) 16:427-33. doi: 10.1097/ACI.0000000000 000303

81. Nwaru BI, Hayes H, Gambling L, Craig LC, Allan K, Prabhu N, et al. An exploratory study of the associations between maternal iron status in pregnancy and childhood wheeze and atopy. Br J Nutr. (2014) 112:2018-27. doi: $10.1017 /$ S0007114514003122
82. Tseng WN, Chen CC, Yu HR, Huang LT, Kuo HC. Antenatal dexamethasone exposure in preterm infants is associated with allergic diseases and the mental development index in children. Int J Environ Res Public Health. (2016) 13:1206. doi: 10.3390/ijerph13121206

83. Yitshak-Sade M, Gorodischer R, Aviram M, Novack L. Prenatal exposure to $\mathrm{H} 2$ blockers and to proton pump inhibitors and asthma development in offspring. J Clin Pharmacol. (2016) 56:116-23. doi: 10.1002/jcph.574

84. Dehlink E, Yen E, Leichtner AM, Hait EJ, Fiebiger E. First evidence of a possible association between gastric acid suppression during pregnancy and childhood asthma: a population-based register study. Clin Exp Allergy. (2009) 39:246-53. doi: 10.1111/j.1365-2222.2008.03125.x

85. Zugna D, Galassi C, Annesi-Maesano I, Baiz N, Barros H, Basterrechea M, et al. Maternal complications in pregnancy and wheezing in early childhood: a pooled analysis of 14 birth cohorts. Int J Epidemiol. (2015) 44:199-208. doi: $10.1093 /$ ije/dyu260

86. Herberth G, Pierzchalski A, Feltens R, Bauer M, Roder S, Olek S, et al. Prenatal phthalate exposure associates with low regulatory Tcell numbers and atopic dermatitis in early childhood: results from the Lina mother-child study. J Allergy Clin Immunol. (2017) 139:1376-9. doi: 10.1016/j.jaci.2016.09.034

87. Hartwig IR, Sly PD, Schmidt LA, van Lieshout RJ, Bienenstock J, Holt PG, et al. Prenatal adverse life events increase the risk for atopic diseases in children, which is enhanced in the absence of a maternal atopic predisposition. J Allergy Clin Immunol. (2014) 134:160-9. doi: 10.1016/j.jaci.2014.01.033

88. Metsala J, Lundqvist A, Virta LJ, Kaila M, Gissler M, Virtanen SM. Mother's and offspring's use of antibiotics and infant allergy to cow's milk. Epidemiology. (2013) 24:303-9. doi: 10.1097/EDE.0b013e31827f520f

89. Lumia M, Luukkainen P, Tapanainen H, Kaila M, Erkkola M, Uusitalo $\mathrm{L}$, et al. Dietary fatty acid composition during pregnancy and the risk of asthma in the offspring. Pediatr Allergy Immunol. (2011) 22:827-35. doi: 10.1111/j.1399-3038.2011.01202.x

90. Macaubas C, de Klerk NH, Holt BJ, Wee C, Kendall G, Firth M, et al. Association between antenatal cytokine production and the development of atopy and asthma at age 6 years. Lancet. (2003) 362:1192-7. doi: 10.1016/S0140-6736(03)14542-4

91. Flores KF, Robledo CA, Hwang BS, Leishear K, Laughon Grantz K, Mendola P. Does maternal asthma contribute to racial/ethnic disparities in obstetrical and neonatal complications? Ann Epidemiol. (2015) 25:392-7. doi: 10.1016/j.annepidem.2015.01.011

92. Kopp MV, Zehle C, Pichler J, Szepfalusi Z, Moseler M, Deichmann $\mathrm{K}$, et al. Allergen-specific $\mathrm{T}$ cell reactivity in cord blood: the influence of maternal cytokine production. Clin Exp Allergy. (2001) 31:1536-43. doi: 10.1046/j.1365-2222.2001.01198.x

93. Liu X, Agerbo E, Schlunssen V, Wright RJ, Li J, Munk-Olsen T. Maternal asthma severity and control during pregnancy and risk of offspring asthma. J Allergy Clin Immunol. (2018) 141:886-92. doi: 10.1016/j.jaci.2017.05.016

94. Lim RH, Kobzik L, Dahl M. Risk for asthma in offspring of asthmatic mothers versus fathers: a meta-analysis. PLoS ONE. (2010) 5:e10134. doi: 10.1371/journal.pone.0010134

95. Liu CA, Wang CL, Chuang H, Ou CY, Hsu TY, Yang KD. Prenatal prediction of infant atopy by maternal but not paternal total IgE levels. J Allergy Clin Immunol. (2003) 112:899-904. doi: 10.1016/j.jaci.2003.08.030

96. Stokholm J, Blaser MJ, Thorsen J, Rasmussen MA, Waage J, Vinding RK, et al. Maturation of the gut microbiome and risk of asthma in childhood. Nat Commun. (2018) 9:141. doi: 10.1038/s41467-018-03150-x

97. Bottcher MF, Jenmalm MC, Bjorksten B, Garofalo RP. Chemoattractant factors in breast milk from allergic and nonallergic mothers. Pediatr Res. (2000) 47:592-7. doi: 10.1203/00006450-200005000-00006

98. Jarvinen KM, Suarez-Farinas M, Savilahti E, Sampson HA, Berin MC. Immune factors in breast milk related to infant milk allergy are independent of maternal atopy. J Allergy Clin Immunol. (2015) 135:1390-3. doi: 10.1016/j.jaci.2014.10.051

99. Fusaro AE, de Brito CA, Taniguchi EF, Muniz BP, Victor JR, Orii $\mathrm{NM}$, et al. Balance between early life tolerance and sensitization in allergy: dependence on the timing and intensity of prenatal and postnatal allergen exposure of the mother. Immunology. (2009) 128:e541-50. doi: $10.1111 /$ j.1365-2567.2008.03028.x 
100. Happle C, Jirmo AC, Meyer-Bahlburg A, Habener A, Hoymann HG, Hennig C, et al. B cells control maternofetal priming of allergy and tolerance in a murine model of allergic airway inflammation. J Allergy Clin Immunol. (2018) 141:685-96. doi: 10.1016/j.jaci.2017.03.051

101. Lima C, Souza VM, Faquim-Mauro EL, Hoshida MS, Bevilacqua E, Macedo MS, et al. Modulation of the induction of lung and airway allergy in the offspring of IFN-gamma-treated mother mice. J Immunol. (2005) 175:35549. doi: 10.4049/jimmunol.175.6.3554

102. Polte T, Hennig C, Hansen G. Allergy prevention starts before conception: maternofetal transfer of tolerance protects against the development of asthma. J Allergy Clin Immunol. (2008) 122:1022-30. doi: 10.1016/j.jaci.2008.09.014

103. Conrad ML, Ferstl R, Teich R, Brand S, Blumer N, Yildirim AO, et al. Maternal TLR signaling is required for prenatal asthma protection by the nonpathogenic microbe Acinetobacter lwoffii f78. J Exp Med. (2009) 206:2869-77. doi: 10.1084/jem.20090845

104. Brand S, Teich R, Dicke T, Harb H, Yildirim AO, Tost J, et al. Epigenetic regulation in murine offspring as a novel mechanism for transmaternal asthma protection induced by microbes. J Allergy Clin Immunol. (2011) 128:618-25. doi: 10.1016/j.jaci.2011.04.035

105. Matson AP, Zhu L, Lingenheld EG, Schramm CM, Clark RB, Selander DM, et al. Maternal transmission of resistance to development of allergic airway disease. J Immunol. (2007) 179:1282-91. doi: 10.4049/jimmunol.179.2.1282

106. Thorburn AN, McKenzie CI, Shen S, Stanley D, Macia L, Mason LJ, et al. Evidence that asthma is a developmental origin disease influenced by maternal diet and bacterial metabolites. Nat Commun. (2015) 6:7320. doi: $10.1038 /$ ncomms 8320

107. Hamada K, Suzaki Y, Goldman A, Ning YY, Goldsmith C, Palecanda A, et al. Allergen-independent maternal transmission of asthma susceptibility. $J$ Immunol. (2003) 170:1683-9. doi: 10.4049/jimmunol.170.4.1683

108. Hubeau C, Apostolou I, Kobzik L. Adoptively transferred allergen-specific $\mathrm{T}$ cells cause maternal transmission of asthma risk. Am J Pathol. (2006) 168:1931-9. doi: 10.2353/ajpath.2006. 051231

109. Hubeau C, Apostolou I, Kobzik L. Targeting of CD25 and glucocorticoidinduced TNF receptor family-related gene-expressing $\mathrm{T}$ cells differentially modulates asthma risk in offspring of asthmatic and normal mother mice. J Immunol. (2007) 178:1477-87. doi: 10.4049/jimmunol.178. 3.1477

110. Walker MT, Green JE, Ferrie RP, Queener AM, Kaplan MH, CookMills JM. Mechanism for initiation of food allergy: dependence on skin barrier mutations and environmental allergen costimulation. J Allergy Clin Immunol. (2018) 141:1711-25. doi: 10.1016/j.jaci.2018.02.003

111. Verhasselt V, Milcent V, Cazareth J, Kanda A, Fleury S, Dombrowicz D, et al. Breast milk-mediated transfer of an antigen induces tolerance and protection from allergic asthma. Nat Med. (2008) 14:170-5. doi: 10.1038/nm1718

112. Turfkruyer M, Rekima A, Macchiaverni P, Le Bourhis L, Muncan V, van den Brink GR, et al. Oral tolerance is inefficient in neonatal mice due to a physiological vitamin A deficiency. Mucosal Immunol. (2016) 9:479-91. doi: $10.1038 / \mathrm{mi} .2015 .114$

113. Matson AP, Thrall RS, Rafti E, Puddington L. Breastmilk from allergic mothers can protect offspring from allergic airway inflammation. Breastfeed Med. (2009) 4:167-74. doi: 10.1089/bfm.2008.0130

114. Matson AP, Thrall RS, Rafti E, Lingenheld EG, Puddington L. IgG transmitted from allergic mothers decreases allergic sensitization in breastfed offspring. Clin Mol Allergy. (2010) 8:9. doi: 10.1186/1476-7961-8-9

115. Jarvinen KM, Westfall J, De Jesus M, Mantis NJ, Carroll JA, Metzger DW, et al. Role of maternal dietary peanut exposure in development of food allergy and oral tolerance. PLoS ONE. (2015) 10:e0143855. doi: 10.1371/journal.pone. 0143855

116. Yamamoto T, Tsubota Y, Kodama T, Kageyama-Yahara N, Kadowaki M. Oral tolerance induced by transfer of food antigens via breast milk of allergic mothers prevents offspring from developing allergic symptoms in a mouse food allergy model. Clin Dev Immunol. (2012) 2012:721085. doi: $10.1155 / 2012 / 721085$

117. Rekima A, Macchiaverni P, Turfkruyer M, Holvoet S, Dupuis L, Baiz $\mathrm{N}$, et al. Long-term reduction in food allergy susceptibility in mice by combining breastfeeding-induced tolerance and TGF-beta-enriched formula after weaning. Clin Exp Allergy. (2017) 47:565-76. doi: 10.1111/cea. 12864

118. Song Y, Liu C, Hui Y, Srivastava K, Zhou Z, Chen J, et al. Maternal allergy increases susceptibility to offspring allergy in association with Th2-biased epigenetic alterations in a mouse model of peanut allergy. J Allergy Clin Immunol. (2014) 134:1339-45. doi: 10.1016/j.jaci.2014.08.034

119. Verhasselt V. Neonatal tolerance under breastfeeding influence: the presence of allergen and transforming growth factor-beta in breast milk protects the progeny from allergic asthma. J Pediatr. (2010) 156:S16-20. doi: 10.1016/j.jpeds.2009.11.015

120. Morita H, Tamari M, Fujiwara M, Motomura K, Koezuka Y, Ichien G, et al. IgE-class-specific immunosuppression in offspring by administration of anti-IgE to pregnant mice. J Allergy Clin Immunol. (2019) 143:1261-4. doi: 10.1016/j.jaci.2018.11.008

121. Noval Rivas M, Burton OT, Wise P, Zhang YQ, Hobson SA, Garcia Lloret $\mathrm{M}$, et al. A microbiota signature associated with experimental food allergy promotes allergic sensitization and anaphylaxis. J Allergy Clin Immunol. (2013) 131:201-12. doi: 10.1016/j.jaci.2012.10.026

122. Stefka AT, Feehley T, Tripathi P, Qiu J, McCoy K, Mazmanian SK, et al. Commensal bacteria protect against food allergen sensitization. Proc Natl Acad Sci USA. (2014) 111:13145-50. doi: 10.1073/pnas.1412008111

123. Feehley T, Plunkett CH, Bao R, Choi Hong SM, Culleen E, Belda-Ferre P, et al. Healthy infants harbor intestinal bacteria that protect against food allergy. Nat Med. (2019) 25:448-53. doi: 10.1038/s41591-018-0324-z

124. Abdel-Gadir A, Stephen-Victor E, Gerber GK, Noval Rivas M, Wang $\mathrm{S}$, Harb $\mathrm{H}$, et al. Microbiota therapy acts via a regulatory $\mathrm{T}$ cell MyD88/ROR $\gamma$ t pathway to suppress food allergy. Nat Med. (2019) 25:116474. doi: 10.1038/s41591-019-0461-z

125. Ghosh MK, Nguyen V, Muller HK, Walker AM. Maternal milk T cells drive development of transgenerational Th1 immunity in offspring thymus. J Immunol. (2016) 197:2290-6. doi: 10.4049/jimmunol.1502483

126. Nakata K, Kobayashi K, Ishikawa Y, Yamamoto M, Funada Y, Kotani $\mathrm{Y}$, et al. The transfer of maternal antigen-specific IgG regulates the development of allergic airway inflammation early in life in an FcRndependent manner. Biochem Biophys Res Commun. (2010) 395:238-43. doi: 10.1016/j.bbrc.2010.03.170

127. Burton OT, Logsdon SL, Zhou JS, Medina-Tamayo J, Abdel-Gadir A, Noval Rivas $\mathrm{M}$, et al. Oral immunotherapy induces IgG antibodies that act through FcgammaRIIb to suppress IgE-mediated hypersensitivity. J Allergy Clin Immunol. (2014) 134:1310-7. doi: 10.1016/j.jaci.2014.05.042

128. Burton OT, Tamayo JM, Stranks AJ, Koleoglou KJ, Oettgen HC. Allergen-specific IgG antibody signaling through FcgammaRIIb promotes food tolerance. J Allergy Clin Immunol. (2018) 141:189-201. doi: 10.1016/j.jaci.2017.03.045

129. Koplin JJ, Allen KJ, Gurrin LC, Peters RL, Lowe AJ, Tang ML, et al. The impact of family history of allergy on risk of food allergy: a populationbased study of infants. Int J Environ Res Public Health. (2013) 10:5364-77. doi: 10.3390/ijerph10115364

130. Thomsen SF. Genetics of asthma: an introduction for the clinician. Eur Clin Respir J. (2015) 2:24643. doi: 10.3402/ecrj.v2.24643

131. Portelli MA, Hodge E, Sayers I. Genetic risk factors for the development of allergic disease identified by genome-wide association. Clin Exp Allergy. (2015) 45:21-31. doi: 10.1111/cea.12327

132. Bonnelykke K, Matheson MC, Pers TH, Granell R, Strachan DP, Alves $\mathrm{AC}$, et al. Meta-analysis of genome-wide association studies identifies ten loci influencing allergic sensitization. Nat Genet. (2013) 45:902-6. doi: $10.1038 /$ ng.2694

133. Thomsen SF, van der Sluis S, Kyvik KO, Backer V. A study of asthma severity in adult twins. Clin Respir J. (2012) 6:228-37. doi: 10.1111/j.1752-699X.2011.00273.x

134. Marenholz I, Grosche S, Kalb B, Ruschendorf F, Blumchen K, Schlags R, et al. Genome-wide association study identifies the SERPINB gene cluster as a susceptibility locus for food allergy. Nat Commun. (2017) 8:1056. doi: 10.1038/s41467-017-01220-0

135. Khan SJ, Dharmage SC, Matheson MC, Gurrin LC. Is the atopic march related to confounding by genetics and early-life environment? A systematic review of sibship and twin data. Allergy. (2018) 73:17-28. doi: $10.1111 /$ all. 13228 
136. Ullemar V, Magnusson PK, Lundholm C, Zettergren A, Melen E, Lichtenstein $\mathrm{P}$, et al. Heritability and confirmation of genetic association studies for childhood asthma in twins. Allergy. (2016) 71:230-8. doi: 10.1111/all.12783

137. Alexander ES, Martin LJ, Collins MH, Kottyan LC, Sucharew H, He H, et al. Twin and family studies reveal strong environmental and weaker genetic cues explaining heritability of eosinophilic esophagitis. J Allergy Clin Immunol. (2014) 134:1084-92. doi: 10.1016/j.jaci.2014.07.021

138. Wegienka G, Johnson CC, Zoratti E, Havstad S. Racial differences in allergic sensitization: recent findings and future directions. Curr Allergy Asthma Rep. (2013) 13:255-61. doi: 10.1007/s11882-013-0343-2

139. Kumar R, Tsai HJ, Hong X, Liu X, Wang G, Pearson C, et al. Race, ancestry, and development of food-allergen sensitization in early childhood. Pediatrics. (2011) 128:e821-9. doi: 10.1542/peds.2011-0691

140. Kaan A, Dimich-Ward H, Manfreda J, Becker A, Watson W, Ferguson A, et al. Cord blood IgE: its determinants and prediction of development of asthma and other allergic disorders at 12 months. Ann Allergy Asthma Immunol. (2000) 84:37-42. doi: 10.1016/S1081-1206(10)62738-X

141. Meulenbroek LA, Knippels LM. Cord blood IgE: fetal or maternal? Clin Exp Allergy. (2015) 45:1012-4. doi: 10.1111/cea.12530

142. Bundhoo A, Paveglio S, Rafti E, Dhongade A, Blumberg RS, Matson AP, Evidence that FcRn mediates the transplacental passage of maternal IgE in the form of IgG anti-IgE/IgE immune complexes. Clin Exp Allergy. (2015) 45:1085-98. doi: 10.1111/cea.12508

143. Tamburini S, Shen N, Wu HC, Clemente JC. The microbiome in early life: implications for health outcomes. Nat Med. (2016) 22:713-22. doi: $10.1038 / \mathrm{nm} .4142$

144. Folsgaard NV, Chawes BL, Rasmussen MA, Bischoff AL, Carson CG, Stokholm J, et al. Neonatal cytokine profile in the airway mucosal lining fluid is skewed by maternal atopy. Am J Respir Crit Care Med. (2012) 185:275-80. doi: 10.1164/rccm.201108-14710C

145. Miles EA, Calder PC. Maternal diet and its influence on the development of allergic disease. Clin Exp Allergy. (2015) 45:63-74. doi: 10.1111/cea.12453

146. von Mutius E, Weiland SK, Fritzsch C, Duhme H, Keil U. Increasing prevalence of hay fever and atopy among children in Leipzig, east Germany. Lancet. (1998) 351:862-6. doi: 10.1016/S0140-6736(97)10100-3

147. Dunder T, Kuikka L, Turtinen J, Rasanen L, Uhari M. Diet, serum fatty acids, and atopic diseases in childhood. Allergy. (2001) 56:425-8. doi: 10.1034/j.1398-9995.2001.056005425.x

148. Wendell SG, Baffi C, Holguin F. Fatty acids, inflammation, and asthma. J Allergy Clin Immunol. (2014) 133:1255-64. doi: 10.1016/j.jaci.2013.12.1087

149. Murphy VE, Gibson PG, Giles WB, Zakar T, Smith R, Bisits AM, et al. Maternal asthma is associated with reduced female fetal growth. Am J Respir Crit Care Med. (2003) 168:1317-23. doi: 10.1164/rccm.200303-374OC

150. Vadas P, Wai Y, Burks W, Perelman B. Detection of peanut allergens in breast milk of lactating women. JAMA. (2001) 285:1746-8. doi: 10.1001/jama.285.13.1746

151. Palmer DJ, Gold MS, Makrides M. Effect of cooked and raw egg consumption on ovalbumin content of human milk: a randomized, double-blind, cross-over trial. Clin Exp Allergy. (2005) 35:173-8. doi: 10.1111/j.1365-2222.2005.02170.x

152. Jarvinen KM, Makinen-Kiljunen S, Suomalainen H. Cow's milk challenge through human milk evokes immune responses in infants with cow's milk allergy. J Pediatr. (1999) 135:506-12. doi: 10.1016/S0022-3476(99) 70175-7

153. Macchiaverni P, Rekima A, Turfkruyer M, Mascarell L, Airouche S, Moingeon $\mathrm{P}$, et al. Respiratory allergen from house dust mite is present in human milk and primes for allergic sensitization in a mouse model of asthma. Allergy. (2014) 69:395-8. doi: 10.1111/all.12332

154. Jarvinen KM, Geller L, Bencharitiwong R, Sampson HA. Presence of functional, autoreactive human milk-specific $\operatorname{IgE}$ in infants with cow's milk allergy. Clin Exp Allergy. (2011) 42:238-47. doi: 10.1111/j.1365-2222.2011.03864.x

155. Jarvinen KM, Suomalainen H. Development of cow's milk allergy in breast-fed infants. Clin Exp Allergy. (2001) 31:978-87. doi: 10.1046/j.1365-2222.2001.01151.x

156. Fedulov AV, Leme AS, Kobzik L. Duration of allergic susceptibility in maternal transmission of asthma risk. Am J Reprod Immunol. (2007) 58:1208. doi: 10.1111/j.1600-0897.2007.00496.x

157. Busse WW, Rosenwasser LJ. Mechanisms of asthma. J Allergy Clin Immunol. (2003) 111:S799-804. doi: 10.1067/mai.2003.158

158. Fedulov AV, Kobzik L. Allergy risk is mediated by dendritic cells with congenital epigenetic changes. Am J Respir Cell Mol Biol. (2011) 44:285-92. doi: $10.1165 / \mathrm{rcmb} .2009-0400 \mathrm{OC}$

159. Herz U, Joachim R, Ahrens B, Scheffold A, Radbruch A, Renz H. Allergic sensitization and allergen exposure during pregnancy favor the development of atopy in the neonate. Int Arch Allergy Immunol. (2001) 124:193-6. doi: 10.1159/000053708

160. Richgels PK, Yamani A, Chougnet CA, Lewkowich IP. Maternal house dust mite exposure during pregnancy enhances severity of house dust mite-induced asthma in murine offspring. J Allergy Clin Immunol. (2017) 140:1404-15. doi: 10.1016/j.jaci.2016.12.972

161. Leme AS, Hubeau C, Xiang Y, Goldman A, Hamada K, Suzaki $\mathrm{Y}$, et al. Role of breast milk in a mouse model of maternal transmission of asthma susceptibility. J Immunol. (2006) 176:762-9. doi: 10.4049/jimmunol.176.2.762

Conflict of Interest Statement: The authors declare that the research was conducted in the absence of any commercial or financial relationships that could be construed as a potential conflict of interest.

Copyright (C) 2019 Fujimura, Lum, Nagata, Kawamoto and Oyoshi. This is an openaccess article distributed under the terms of the Creative Commons Attribution License (CC BY). The use, distribution or reproduction in other forums is permitted, provided the original author(s) and the copyright owner(s) are credited and that the original publication in this journal is cited, in accordance with accepted academic practice. No use, distribution or reproduction is permitted which does not comply with these terms. 